\title{
Konservative Kulturkritik in der frühen Bundesrepublik Deutschland. Die Abendländische Akademie in Eichstätt (1952-1956)*
}

\section{Von Rudolf Uertz}

Mit der Etablierung des parlamentarischen Systems der Bundesrepublik und der ersten Bundesregierung, der von Konrad Adenauer geführten Koalition aus CDU/CSU, FDP und den kleineren konservativen Parteien, meldeten sich sogleich die Kritiker der neuen Staats- und Gesellschaftsordnung zu Wort. Enttäuscht zeigten sich viele Intellektuelle, Publizisten, Wissenschaftler und auch Kirchenvertreter über das „Verspielen der Chance“, die sich ihrer Meinung nach angesichts der „Stunde Null“" nach 1945 eröffnet hatte. Die Kritik an der neuen bundesrepublikanischen Ordnung speiste sich aus Zukunftsentwürfen, die gegensätzlicher kaum sein konnten. Gemeinsames Merkmal war ein hohes $\mathrm{Ma} \beta$ an moralischer Begründung. Der Aufbau einer neuen Gesellschaftsordnung wurde nicht bloß als Frage einer äußerlich effektiven Organisation verschiedener gesellschaftlicher Interessen verstanden, sondern vielmehr als umfassende Beheimatung des einzelnen und der Gesellschaft in einer übergreifenden, sinnstiftenden ,gerechten Ordnung“, die - nach der Pervertierung aller humanen Werte im Dritten Reich - der wahren geistig-kulturellen Herkunft der Deutschen entsprechen sollte, nämlich der europäisch-abendländischen Idee. ${ }^{1}$

Walter Dirks, der linkskatholische Publizist, war einer der ersten, der 1950 in den „Frankfurter Heften“ die westdeutsche Gesellschaft auf dem Weg in die „Restauration“ sah. ${ }^{2}$ Als „,restaurativ“ charakterisierte er vor allem die vermeintliche Wiederaufrichtung des alten Parteiensystems von Weimar - träumte Dirks doch stattdessen von einer Art christlicher Labour Party, welche die politischen Zerklüftungen der Arbeiterschaft und der durch den Krieg entwurzelten Bevölkerung überwölben sollte. Von der politischen Sammlungsbewegung der christlich-demokratischen Union war er enttäuscht, da in ihr die alten

* Überarbeitete Fassung der öffentlichen Probevorlesung vom 19. Juli 2000 im Rahmen meiner Habilitation an der Geschichts- und Gesellschaftswissenschaftlichen Fakultät der Katholischen Universität Eichstätt.

1 Kritik an gesellschaftlichen Entwicklungen, auch wenn sie sich auf den ausschnitthaften Bereich des Staatsaufbaus konzentrieren, wird daher nicht nur als Gesellschaftskritik i.e.S. verstanden, sondern immer auch als Kulturkritik.

2 Walter DiRKs, Der restaurative Charakter der Epoche, in: Frankfurter Hefte 5. Jg. (1950), S. $942 \mathrm{ff}$. 
politischen und wirtschaftlichen Eliten wieder das Sagen hätten; insbesondere mit der (Sozialen) Marktwirtschaft schreite man zur Restauration des „Kapitalismus“. Für Dirks war dies „Verrat an den europäischen Werten“, die er mit Begriffen wie „Abendland“ oder „abendländisches Menschenbild“ umschrieb. Ein Aufsatz aus dem Jahre 1946 schließt mit den programmatischen Worten: „Das Abendland wird sozialistisch sein, oder es wird nicht sein. Zerfällt Europa in das ,Abendland " und in den ,Sozialismus', so zerfällt es in sich selbst." ${ }^{3}$

Auch in christlich-liberalen Kreisen war der Topos „Abendland“ verbreitet. Einer der bedeutendsten Vertreter dieser Richtung war der in Genf lebende deutsche Nationalökonom Wilhelm Röpke. Für ihn lag im Begriff des ,,abendländischen Denkens" die Freiheit der menschlichen Person, die dem Staat Schranken setzt. Diese emanzipatorische Kraft des abendländischen Denkens sieht Röpke bereits in den Reformbewegungen des Mittelalters angelegt, aus deren Traditionsbestand auch Humanismus und aufgeklärtes Naturrecht stammten. „Abendland“ sei eine Synthese von antiker, mittelalterlicher und neuzeitlicher Kultur, die in Umschreibungen wie der christlichen Lehre des „Personalismus“ ihren zündenden Ausdruck finde. ${ }^{4}$

Der Begriff Abendland, vielfach auch als Synonym für den Europagedanken verstanden, lag nach dem Zweiten Weltkrieg gewissermaßen in der Luft - galt es doch, die Konzepte für den politisch-gesellschaftlichen Neuaufbau theoretisch und historisch zu fundieren und tragfähige Leitbilder für die nationale, die europäische und die westlich-atlantische Neuordnung zu finden. Die neuen Konzepte mussten in eine griffige Formel gefasst und zugleich und vor allem gegenüber dem Nationalsozialismus und dem Kommunismus abgegrenzt werden.

Der Publizist Emil Franzel wandte sich 1946 in der Zeitschrift „Neues Abendland “5 gegen jedweden Versuch, den christlichen Abendlandgedanken mit neuzeitlichen Ordnungsideen zu vermengen. Sozialismus, Nationalsozia-

3 Walter DiRKs, Das Abendland und der Sozialismus, in: Frankfurter Hefte 1. Jg., Heft 3 (1946), S. 67 ff.; hier S. 76.

4 Wilhelm RÖPKE, Maß und Mitte, Bern 2. Aufl. 1950, S. 16 ff., entfaltet dort ideengeschichtlich-systematisch die aus dem abendländischen Denken resultierende Idee der sittlichen Autonomie („Gewissensfreiheit“, „Unabhängigkeit“) sowie der personalistischen, humanistischen und antiautoritären Lehre des Christentums. Zur verantwortlichen Person gehört für Röpke deren Selbststand hinsichtlich freiheitlicher Wirtschafts-, Rechts- und Staatsideen. Diese Entwicklung sieht Röpke bereits im mittelalterlich-scholastischen Naturrecht angelegt (Nominalismus), womit er Abälard als Vorläufer des Erasmus und des christlichen Humanismus würdigt.

5 Das „Neue Abendland“ knüpft an das „Abendland. Deutsche Monatshefte für europäische Kultur, Politik und Wirtschaft", Gilde-Verlag, Köln-Berlin-Wien (1926-1930) an. Dessen Herausgeber waren führende Politiker des Zentrums und christlich-sozialer Parteien sowie katholische Intellektuelle aus dem Rheinland, aus Westfalen, Bayern und Österreich wie Konrad Beyerle, Theodor Brauer, Goetz Briefs, Wilhelm Hamacher, Hugo Graf Lerchenfeld, Hermann Platz, Friedrich Schreyvogl sowie Bundeskanzler Prälat Ignaz Seipel. Zum Abendland- 
lismus, Bolschewismus, Humanismus und Liberalismus seien allesamt antichristlich und stünden der abendländischen Geisteshaltung diametral entgegen. Die Kritik anderer weltanschaulicher Richtungen aufgreifend, stimmt er wohl dem Befund zu, alle gegenwärtig um Anerkennung ringenden politischen Bewegungen im Nachkriegsdeutschland seien „restaurativ“, insofern sie an Staats- und Gesellschaftsvorstellungen des 18. und 19. Jahrhunderts anknüpften. Aber entscheidend für ihre Beurteilung könne und dürfe nur ein fester Maßstab sein: die „christlich-abendländische Tradition“. Damit beanspruchte die Zeitschrift „Neues Abendland“ das Deutungsmonopol dieses Begriffs. ${ }^{6}$

Die Mitarbeiter der Zeitschrift standen sowohl in Opposition zur Neuordnung der Bundesrepublik als auch in einer Zwei-Fronten-Stellung hinsichtlich anderer Kritiker, wenn sie sich entschieden von dem Kurs der „Frankfurter Hefte" um Walter Dirks und Eugen Kogon, ${ }^{7}$ zugleich aber auch von liberalchristlichen Ideen abgrenzten. Was ihre an der rechtsstaatlichen Verfassung geübte Kritik ,von rechts“ besonders pikant machte, war der Umstand, dass im Kreis um das „Neue Abendland“ namhafte Vertreter des Regierungsbündnisses aus CDU, CSU, FDP und Deutsche Partei, ${ }^{8}$ Mitglieder der Länderparlamente sowie hohe Bundesrichter, Diplomaten und Kirchenvertreter mitwirkten - Persönlichkeiten also, die ihren Eid auf die freiheitlich-demokratische Grundordnung der Bundesrepublik Deutschland abgelegt hatten.

Die engen Verbindungen von Prominenten aus Politik, Justiz, Gesellschaft und Kirchen zur Gruppe um das „Neue Abendland“ haben dieser schon früh

Kreis der Zwischenkriegszeit vgl. Guido MüLLER/Vanessa PLICHTA, Zwischen Rhein und Donau. Abendländisches Denken zwischen deutsch-französischen Verständigungsinitativen und konservativ-katholischen Integrationsmodellen 1924-1957, in: Zeitschrift für Geschichte der Europäischen Integration, Nr. 1, Bd. 5 (1999), S. 17 ff. - Zu den Abendlandvorstellungen vgl. Heinz HürTEN, Der Topos vom christlichen Abendland in Literatur und Publizistik nach den beiden Weltkriegen, in: Albrecht LANGER (Hg.), Katholizismus, nationaler Gedanke und Europa seit 1800, Paderborn 1985, S. 131 ff.; Jonas JosT, Der Abendland-Gedanke in Westdeutschland nach 1945. Versuch und Scheitern eines Paradigmenwechsels in der deutschen Geschichte nach 1945, Phil. Diss. Hannover 1994; Johann Baptist MüLLER, Der abendländische Topos in der konservativen Denkfamilie der Vor- und Nachkriegszeit, in: Reinhard C. Meier-Walser/Bernd Rill (Hg.), Der europäische Gedanke. Hintergrund und Finalität, München 2000, S. $133 \mathrm{ff}$.

6 Diese Theorie des Abendlandbegriffs basierte einerseits auf einer metaphysisch-naturrechtlichen Argumentation der neuscholastischen Theologie und Philosophie, die die Vorstellungen liberal-demokratischer Verfassungs- und Staatstheorie schon vom Prinzip her als unvereinbar mit dem katholischen Denken ablehnte; daneben orientierten sich die Staats- und Gesellschaftstheorien auch an traditionalistischen, ständestaatlich-korporativen Ideen und Vorstellungen des alten Reichsgedankens. Zum Reichsgedanken im Katholizismus der Zwischenkriegszeit vgl. Klaus BREUnING, Die Vision des Reiches. Deutscher Katholizismus zwischen Demokratie und Diktatur (1929-1934), München 1969.

7 Vgl. Emil Franzel, Walter Dirks und der Kommunismus, in: NA 7 (1952), S. 129 ff.

8 Auch Repräsentanten der traditionalistisch-konservativen Bayernpartei, wie etwa Elimar Freiherr von Fürstenberg, MdB bis 1953, nahmen an den Akademietagungen teil, traten aber als Referenten und Debattenredner nicht sonderlich in Erscheinung. 
das publizistische und wissenschaftliche Interesse gesichert. Für Helga Grebing, die 1971 die erste größere Studie zum „Neuen Abendland“ vorlegte, ist diese Gruppe mit der wichtigste Beleg für ihre Restaurationsthese, die sie auf Walter Dirks stützt. Kennzeichen der Epoche der frühen Bundesrepublik sei das „Wiederanknüpfen aller politischen Kräfte an die Zeit vor Hitler und der Versuch der Wiederherstellung der aus dieser Zeit stammenden Positionen, Rechte und Besitzstände“" gewesen. ${ }^{10}$ Für Martin Greiffenhagen bietet die Gruppe um das „Neue Abendland“ „reiches Anschauungsmaterial“ für die frühe Bundesrepublik, für deren Restauration die katholische Naturrechtslehre das theoretische Fundament geliefert habe. ${ }^{11}$ Diese These ist allerdings schon deshalb fragwürdig, weil der Protestantismus, auch soweit er zum Konservatismus gerechnet wird, das Naturrecht - jedenfalls in der beschriebenen neuscholastisch-kirchlichen Variante - weithin ablehnt. ${ }^{12}$ Dessen ungeachtet scheint den Verfechtern der Restaurationsthese die Gruppe um das Neue Abendland gerade den Nachweis zu erbringen, dass sich die Protestanten dem katholisch-konservativen (Naturrechts-)Denken weitgehend angeschlossen hätten, zumal doch in diesem Kreis auch prominente evangelische Theologen aktiv gewesen seien. ${ }^{13}$

9 Die erste wissenschaftliche Beschäftigung mit der Gruppe um das neue Abendland bot Thomas Ellwein, Klerikalismus in der deutschen Politik, München 2. Aufl. 1955, S. 212 ff., $245 \mathrm{ff}$.

10 Helga Grebing, Konservative gegen die Demokratie. Konservative Kritik an der Demokratie in der Bundesrepublik nach 1945, Frankfurt a. M. 1971, S. 16.

11 Martin Greiffenhagen, Das Dilemma des Konservatismus in Deutschland, Frankfurt a.M. 1986, S. 273, 309 f. Die Gruppe um das neue Abendland wird - unter Verweis auf Helga Grebing - als repräsentativ für den „katholischen Konservatismus“ angeführt, der mit seiner „Ontologie [...] der älteren Naturrechtslehre“ die Grundlage für die „konservative Theorie“ bereitgestellt habe.

12 Für M. GReiffenhagen (wie Anm. 11), S. 269 ff. führt die ,pessimistische Anthropologie des Konservatismus [...] zu einer radikalen Unterscheidung von Moral und Politik“. Für den Konservatismus als Traditionalismus ist diese These zutreffend (Greiffenhagen belegt dies bei Carl SchmitT, Politische Theologie, München 2. Aufl. 1934, und Joseph de MaISTRE, Vom Papst. [1819], dt. Frankfurt 1822); für das „katholische Naturrechtsdenken“, das Greiffenhagen nicht genügend vom Traditionalismus unterscheidet, gilt diese (augustinische) Grundthese jedoch nicht. Vielmehr schließt sich das katholische Naturrecht Thomas von Aquin an, der trotz der durch die Erbsünde verletzten Menschennatur eine metaphysisch begründete Sittenlehre annimmt. De Maistre und Carl Schmitt sind keine Vertreter des katholischen Naturrechts. Zur Kritik am katholischen Naturrechtsdenken durch protestantische CDU-Mitglieder vgl. Hans ASMUSSEN, Die evangelischen Kirchen nach der Wahl, in: NA 8 (1953), S. 723 f.; vgl. Rudolf UERTZ, Christentum und Sozialismus in der frühen CDU. Grundlagen und Wirkungen der christlich-sozialen Ideen in der Union 1945-1949, Stuttgart 1981, S. 40 ff.

13 Die These, ,dass sich die Protestanten (in der CDU/CSU) den naturrechtlich argumentierenden Katholiken weitgehend an(ge)schlossen" hätten, vertritt Gerhard KRAIKER, Politischer Katholizismus in der BRD. Eine ideologiekritische Analyse, Stuttgart 1972, S. 8, wobei auch für Kraiker die Beiträge in der Zeitschrift „Neues Abendland“ als Belege für den restau- 
Die jüngere Zeitgeschichtsforschung nimmt in der „Neuvermessung“ der 50er Jahre (Axel Schildt) von solchen Überzeichnungen Abstand. ${ }^{14}$ Der Restaurationsbegriff wird als diffus kritisiert, da sich immerhin die Frage stelle, ,was denn nun restauriert worden sei“. Mit Hans-Peter Schwarz plädiert Axel Schildt dafür, der Heterogenität der Nachkriegsentwicklung Rechnung zu tragen und „die in jeder Hinsicht aufregenden und interessanten gesellschaftlichen Wandlungsvorgänge in den fünfziger Jahren“ in den Blick zu nehmen. ${ }^{15}$ Von einer „Modernisierung unter ,konservativen Auspizien“" zu sprechen (Christoph Kleßmann) sieht Schildt als problematisch an, da diese Kennzeichnung den Wandel und die wirtschaftlichtechnische Modernisierung nicht hinreichend zum Ausdruck bringe. ${ }^{16}$ Andererseits dürfe man jedoch die Gegentendenzen traditionalistisch-konservativer Kreise nicht ignorieren, die in die Unionsparteien hinein verwoben waren. Es sei schlüssiger von einer „Formveränderung des Konservatismus“ als einem breitgefächerten ideenpolitischen Spektrum auszugehen, innerhalb dessen die ,kultur-pessimistische [...] zugunsten einer heroisch-sachlichen Strömung zurückgedrängt" ${ }^{\text {“ }}$ worden sei. ${ }^{17}$

rativen Charakter der frühen Bundesrepublik fungieren, den er mit „Rechristianisierung“ gleichsetzt. Im Unterschied zu Grebing und Greiffenhagen vermag Kraiker wohl den Naturrechtscharakter der katholischen Soziallehre, insbesondere deren sozialreformerischen Gehalt, präziser zu erfassen, doch sieht er im katholischen Naturrecht (hier stimmt er mit den beiden Genannten wieder überein) eine autoritär-heteronome Theorie, für die vor allem das Neue Abendland repräsentativ sei. Das Problem der ideologiekritischen Arbeiten aus den 1970er Jahren ist, dass die Autoren offenbar im katholischen Naturrecht - der Selbststilisierung der Katholischen Kirche und kirchlicher Kreise folgend - den authentischen Ausdruck des abendländischen Geistes sehen, der keinerlei Spielraum für personal-verantwortungsethische bzw. liberalchristliche Ansätze bietet, wie sie etwa Röpke formuliert (vgl. unten Anm. 73). In Folge dessen sollen Ständegedanke, berufsständische Ordnung, Autoritätsanspruch (des kirchlichen Lehramtes) u.a. den „,christlichen Charakter" der Gesamtepoche in einem betont konservativen Sinne nachweisen, ohne das wesentlich differenziertere christliche ideenpolitische Spektrum (Protestantismus, christlicher Liberalismus, Liberalkatholizismus, Kulturchristentum) genügend in den Blick zu nehmen. Ähnlich argumentiert auch Volker OTTO, Das Staatsverständnis des Parlamentarischen Rates. Ein Beitrag zur Entstehungsgeschichte des Grundgesetzes für die Bundesrepublik Deutschland, Düsseldorf 1971, S. 198 ff., der die gesamte CDU/CSU-Fraktion im Parlamentarischen Rat dem organischen Staatsdenken verbunden sieht. Zur Rolle der Unionsparteien bei der Beratung des Grundgesetzes vgl. Die CDU/CSU im Parlamentarischen Rat. Sitzungsprotokolle der Unionsfraktion, bearbeitet und eingeleitet von Rainer SALZMANN (Forschungen und Quellen zur Zeitgeschichte, Bd. 2), Stuttgart 1981.

14 Zur Zeitgeschichtsforschung der 50er Jahre vgl. Anselm DoERING-MANTEUFFEL (Hg.), Adenauerzeit. Stand, Perspektiven und methodische Aufgaben der Zeitgeschichtsforschung (1945-1967), Bonn 1993.

15 Axel SchiLDT, Zwischen Abendland und Amerika. Studien zur westdeutschen Ideenlandschaft der 50er Jahre, München 1999, S. 4; vgl. Hans-Peter SCHWARZ: ,Geschichtsschreibung und politisches Selbstverständnis. Die Geschichte der Bundesrepublik Deutschland Herausforderung für die Forschung “, in: Aus Politik und Zeitgeschichte 36/1982, S. 3 ff., hier: S. 6.

16 Vgl. Christoph KLessmann, Ein stolzes Schiff und krächzende Möwen. Die Geschichte der Bundesrepublik und ihre Kritiker, in: Geschichte und Gesellschaft 11 (1985), S. 476 ff., hier: S. 485.

17 Axel SCHILDT, Zwischen Abendland und Amerika (wie Anm. 15), S. 4. 
Die jüngeren zeitgeschichtlichen Darstellungen der Gruppe um das Neue Abendland zeichnen ein sehr viel differenzierteres Bild. Zugleich sind ihre ideengeschichtlichen Analysen weit weniger ideologiekritisch als die Beiträge aus den frühen 70er Jahren. Bemerkenswerterweise werden nun zum einen mit der eher beschreibenden Darstellungsform theologisch-philosophische Aspekte weitgehend ausgeklammert, ${ }^{18}$ zum anderen wird eine Auseinandersetzung mit den Methoden und Ergebnissen der vorangegangenen Untersuchungen nicht angestrebt.

Damit aber bleiben die politischen Vorstellungen, wie sie in den Tagungen der Abendländischen Akademie Eichstätt geäußert wurden, in einem wesentlichen Punkt unbeleuchtet. Diesen Tagungen wird sich die folgende Studie insbesondere widmen. Sie zielt darauf ab, den Stellenwert der Kultur- und Gesellschaftskritik der Zeitschrift „Neues Abendland“ und ihre Haltung zum Grundgesetz der Bundesrepublik Deutschland unter sozialethischen und verfassungstheoretischen Gesichtspunkten zu erfassen. Die alternativen Staatsideen sollen mit einzelnen Gegenstimmen aus dem Teilnehmerkreis der Abendländischen Akademie Eichstätt verglichen und in einer Schlussbetrachtung ideengeschichtlich eingeordnet werden. Meine Darstellung wird den Entwicklungsschritten der Gruppe um das „Neue Abendland“ folgen. Es gilt nämlich, die Zeitschrift „Neues Abendland“ von der Abendländischen Aktion, näherhin ihrer programmatisch-politischen Initiative, dem „Abendländischen Manifest", zu unterscheiden, was seinerseits noch einmal von der Struktur und den Zielen der Abendländischen Akademie abzuheben ist.

Entsprechend ergibt sich folgende Gliederung: (1) Vom „Neuen Abendland“ zur Abendländischen Aktion; (2) „Das Manifest der Abendländischen Aktion“; (3) Von der Abendländischen Aktion zur Abendländischen Akademie; (4) Zusammenfassung und Ergebnisse. Die Untersuchung stützt sich vor allem auf die Jahrgänge 1946 bis 1958 der Zeitschrift „Neues Abendland“ (NA), die Dokumentationen der Akademietagungen in Eichstätt von 1952 bis 1956 und die einschlägigen Presseberichte. ${ }^{19}$

18 Nach Axel ScHILDT, Zwischen Abendland und Amerika (wie Anm. 15), S. 22 f., rekurriert die ,Abendland-Ideologie [...] zwar immer wieder auf theologische Argumentationsfiguren, aber es handelte sich doch um eine politische Ideologie“. Das ist selbstredend zutreffend, doch sollte dies nicht hindern, den theologisch-philosophischen Hintergrund dieser nach politischer Wirksamkeit strebenden Forderungen - auch gemäß dem Selbstverständnis der Autoren - gründlicher auszuleuchten.

19 Zur Gründung der Abendländischen Akademie vgl. Axel ScHILDT, Zwischen Abendland und Amerika (wie Anm. 15), S. 56 ff. Unterlagen über die Abendländische Akademie und die Jahrestagungen befinden sich im Diözesan-Archiv Eichstätt, ferner im Fürstlich-WaldburgZeil'schen Gesamtarchiv in Leutkirch. 


\section{Vom „Neuen Abendland“ zur Abendländischen Aktion}

Die Zeitschrift „Neues Abendland“ wurde von dem Verleger Johann Wilhelm Naumann ${ }^{20}$, zu dessen Verlag auch die „Deutsche Tagespost“" gehörte, im Jahre 1946 gegründet. Das „Neue Abendland“ warb mit dem Slogan: „Die kompromisslos-christliche Monatsschrift für Politik, Kultur und Geschichte“.

Im Einführungsartikel der ersten Nummer beschreibt Naumann die Zielsetzung seiner Zeitschrift mit folgenden Worten:

„Der Begriff Abendland hat in der Abwandlung seiner geschichtlichen Bedeutung als einer einheitlichen Kulturauffassung des westlichen und mittleren Europas nur eine Auslegung ermöglicht und erfahren: die christliche. Weder die geographische noch die volkliche Zusammensetzung Europas, sondern eine geistige Haltung gaben ihm einen Sinn. Antike und Christentum, Juno und Ecclesia, humanitas und caritas prägten ihn; im mittelalterlichen Universalismus war er verwirklicht. - Wer auch immer jeweils nach der Zerstörung der abendländischen Einheit die Ursachen des ,Unterganges des Abendlandes' untersucht hat, kam zu der gleichen Feststellung, nämlich jener: dass die Zerstörung [...] bereits begonnen hat in der Sucht der ratio, Dinge zu erklären, die nur glaubensmäßig zu sehen und zu finden sind.“21

Als „Vater der Irrungen“ klagt Naumann Abälard an; der Nominalismus „war der Anfang der Lockerung einer einheitlichen Geistesverfassung des Mittelalters". Mit Hilfe dieser Schablone hat der Herausgeber des „Neuen Abendlands“ keine Mühe, sämtliche neuzeitlichen politischen und philosophischen Bewegungen als Verfallserscheinungen zu qualifizieren, als Systeme, die der göttlichen und natürlichen Ordnung widersprechen und der Selbstherrlichkeit des Individuums frönten. Der dichotomische Charakter dieser Weltsicht wird augenscheinlich, wenn man bedenkt, dass Naumann in die Genealogie der abendländischen Verfallsgeschichte neben Kommunismus, Sozialismus und Nationalsozialismus selbstverständlich auch den Liberalismus einreiht. Das liberale Verfassungsden-

20 Johann Wilhelm Naumann (1897-1956), geb. in Köln, Studium der Philosophie, war bereits in der Weimarer Republik für katholische Zeitungen als Journalist tätig und arbeitete seit 1937 für das Päpstliche Missionswerk. Ende 1945 wurde er zum Vorsitzenden des „Vereins der Bayerischen Zeitungsverleger" gewählt und erhielt von der amerikanischen Besatzungsmacht die Lizenz für die „Schwäbische Landeszeitung“; 1948 wurde er Herausgeber der „Augsburger Tagespost“. Das „Neue Abendland“ erschien bis 1951 im Hausverlag der „Schwäbischen Landeszeitung“; ab 1951 gab Naumann die „Deutsche Tagespost“ (heute: „Die Tagespost“) heraus. Diese und die folgenden biographischen Angaben verdanken sich Doris von der BRELIE-LEWIEN, Katholische Zeitschriften in den Westzonen 1945-1949. Ein Beitrag zur politischen Kultur der Nachkriegszeit, Göttingen 1986, S. 77 ff.; ferner Axel SCHILDT, Zwischen Abendland und Amerika (wie Anm. 15).

21 Johann Wilhelm NaUmAnN: Neues Abendland, in: NA 1 (1946), S. 1 ff.; vgl. ferner DERS., Der „Fürst dieser Welt“, in: NA 3 (1948), S. 257 ff. 
ken basiere auf dem Gesellschaftsvertrag Rousseaus, der keine Rückbindung des Individuums an die göttlichen und natürlichen Gesetze kenne. Parlamentarismus und demokratischer Rechtsstaat seien bloße Kaschierung des säkularistischen Zeitgeistes, der notwendigerweise Familie, Staat und Gesellschaft zersetze. Von dieser Beurteilung gelangt das „Neue Abendland“ zu der These, dass die säkularistische Ordnung von Weimar mit dem „Gesetz der bloßen Zahl“ bereits den Todeskeim in sich getragen habe. Die neue Ordnung des Nachkriegsdeutschlands müsse sich davor hüten, erneut einen solchen Verfassungstyp anzustreben. Davor könne nur der Gedanke des ,,christlichen Abendlands“ bewahren. ${ }^{22}$

Wer allerdings nur die Editorials des „Neuen Abendlands“ liest, wird kaum die Ideenvielfalt vermuten, die hier publiziert wird. So öffnet sich die Zeitschrift durchaus auch Autoren, die weder dem katholischen noch dem protestantischen Spektrum zuzuordnen sind. Zu nennen ist etwa Franz Borkenau, der zwar ein Faible für kulturchristliche Betrachtungen hat, aber schwerlich die programmatischen Richtlinien der Redaktion geteilt haben dürfte. Bei vielen Beiträgen handelt es sich zudem um Fachstudien oder Essays aus den Disziplinen Literatur, Geschichte, Kunst - Beiträge, die ein teilweise sehr viel differenzierteres Verständnis von abendländischer Kultur pflegen. Aber bezogen auf den engeren Mitarbeiterstab und die von diesem traktierten Themen Staat - Verfassung Gesellschaft sind die ersten Jahrgänge der Zeitschrift fraglos von jener doktrinären Haltung geprägt, wie sie das Editorial des Herausgebers vorzeichnet.

Das „Neue Abendland“ enthielt eine Rubrik „Staatswissenschaftliche Rundschau“, in der das politische und gesellschaftliche Programm näher vorgestellt wurde. In den Folgenummern, so hieß es im zweiten Heft 1946, wolle man „Beiträge zur Verfassungsfrage“ unterbreiten. Hierbei gehe es vor allem darum, den modernen mechanistischen Formaldemokratien (der Französischen Revolution und der Weimarer Verfassung) die alten - mehr oder minder - ,organischen Demokratien“" gegenüberstellen, zu denen neben der Schweiz und England auch die USA gezählt würden. Als geistiger Vorfahr wird der Konterrevolutionär Joseph de Maistre verehrt, desgleichen sieht man sich in der ,katholisch-sozialen und katholisch-staatswissenschaftlichen Tradition der Görres, Jarcke, Buß, Jörg, Mallinckrodt und Vogelsang“ stehend. ${ }^{23}$ Mit der Metapher „organische Gesell-

22 Vgl. auch Johann Wilhelm Naumann, Altes und neues Abendland, Augsburg 1948.

23 Föderalismus und Verfassung, in: NA 1 (1946), S. 23 ff. Das NA gibt zu erkennen, dass es in der Nachfolge der rechten, integralistischen Zentrumstradition steht und im Konflikt zwischen der CDU und der neu gegründeten Deutschen Zentrumspartei zugunsten der letzteren votiert. Der Artikel Die Zentrumspartei in: NA 1 (1946), S. 23 ff., plädiert vorsichtig, aber dennoch bestimmt für eine konfessionelle katholische Partei, da nur sie auf dem Boden des Naturrechts stehe, der reformatorische und der rationalistische Protestantismus hingegen - ,wie der Atheismus“ - sich nicht zum Naturrecht von Plato bis Thomas, ,sondern zum individualistischen Pseudo-Naturrecht der Aufklärung" bekenne. Zum Stellenwert des Zentrumsgedankens im NA vgl. den Artikel Hermann Mallinckrodt, in: NA 1 (1946), S. 25 ff. 
schaftsordnung“, ein Synonym für die abendländische Ordnungsidee, knüpfte man an die Theorie der päpstlichen Staatslehre, insbesondere Papst Leos XIII. an, wie sie von einzelnen katholischen Sozialethikern und Zentrumspolitikern des rechten Flügels im Kaiserreich und in der Zwischenkriegszeit verstanden wurde.

Tragend war der Ständegedanke. Dahingehende Vorstellungen enthielten zwar mehr „Kritik“ und nur bedingt Ansätze zu einem praktischen Staatskonzept, aber dieses Modell eines natürlichen Gesellschaftsgebildes sei in der Enzyklika „Quadragesimo anno“ Papst Pius' XI., „Über die gesellschaftliche Ordnung" (1931), zu den obersten christlichen Ordnungsgrundsätzen erhoben worden. Mit Hilfe der päpstlichen Soziallehre gelte es nun, die „Formaldemokratie" des Rationalismus abzuwehren, wie sie sich mittlerweile in den neuen Länderverfassungen abzeichne. ${ }^{24}$ Einwände, dass der sogenannte „christliche Ständestaat" der Österreichischen Verfassung vom Mai 1934 äußerst bedenkliche Formen angenommen habe, werden mit der Bemerkung vom Tisch gewischt, es sei dem Dollfuß-Regime eben nicht gelungen, eine Ständeordnung nach dem Vorbild der Enzyklika einzurichten. ${ }^{25}$ Hinsichtlich der wahren bzw. organischen Volksdemokratie, die man der falschen, d.h. mechanistisch-pluralistischen entgegenstellte, berief man sich auf die Weihnachtsansprache Pius' XII. von $1944 .{ }^{26}$

\section{2. „Das Manifest der Abendländischen Aktion“}

Die Enttäuschung über die parlamentarischen Verfassungen in den Ländern und im Bund schlug im Laufe des Jahres 1951 im „Neuen Abendland“ um in ein politisches Aktionsprogramm. Die Kritik an der bundesrepublikanischen Kultur nahm zu: Man beklagte das Umsichgreifen von Pornographie, die Zügellosigkeit in Film und Theater, das „Dirnenwesen auf der Straße und in Nachtlokalen“ - kurz: die allgemeine „Nivellierung der Massengesellschaft auf unterstem Niveau“. Politikern und Regierung unterstellte man wohl subjektiv guten Willen; die tiefere Ursache des Kulturverfalls machte man in der neuen Verfassung aus. Das in zahlreichen Artikeln, vor allem von Emil Fran-

24 Bayern, so wird vermerkt, könne durch Bildung einer ständischen Ordnung auf diesem Wege vorangehen. Zu deren politisch-rechtlichem Aufbau vgl. unten meine graphische Darstellung des Staatsaufbaus nach dem Abendländischen Manifest.

25 Nicht Karl Freiherr von Vogelsang (1818-1890) sei das Versagen des österreichischen „,christlichen Ständestaats“ anzulasten, sondern der liberalkatholischen Schule M.-Gladbachs: Schmitz, Dobretsberger, Kühr und Meßner hätten sich für diesen Staat, dessen Funktionäre sie gewesen seien, eingesetzt und die Forderung der Enzyklika „Quadragesimo anno“ „nach berufsständischer Wirtschaftsreform in eine solche nach einem ständischen Staat“ verkehrt ( $F \ddot{o}$ deralismus und Verfassung, in: NA 1 [1946], S. 23 ff.).

26 Monarchie oder Demokratie?, in: NA 1 (1946), S. 23 ff. 
zel, geäußerte Unbehagen wird ordnungspolitisch kanalisiert und verschafft sich Luft in der Forderung nach einer Revision des Grundgesetzes. ${ }^{27}$

Im April 1951 wurde die Zeitschrift „Neues Abendland“ aus dem NaumannVerlag in den neugegründeten Verlag „Neues Abendland“ überführt. Verlagseigentümer wurde Fürst Erich zu Waldburg-Zeil28, Herausgeber Gerhard $\mathrm{Kroll}^{29}$. In einer Leserinformation heißt es: Die Freunde des christlich-abendländischen Gedankens wollen es „keineswegs bei der Kritik bewenden lassen“, sondern ihrer Zielsetzung durch die Gründung der Abendländischen Aktion „größere Wirksamkeit [...] verleihen“. Man trete nun in die „Phase der kämpferischen Auseinandersetzung “ ein. ${ }^{30} \mathrm{Zu}$ den Mitgliedern der Gründungsversammlung der Abendländischen Aktion im August 1951 in München zählen auch evangelische Christen, so etwa der Redaktionsmitarbeiter des „Neuen Abendlands" Wolfgang Heilmann aus Bamberg. ${ }^{31}$ Im Zentrum der Gründungsversammlung standen die Referate von Professor Georg Stadtmüller und Gerhard Kroll; letzterer hatte das politische Programm der Aktion Anfang 1951 im 150-seitigen „Manifest der Abendländischen Aktion“ zusammengefasst. ${ }^{32}$ Als CSU-Abgeordneter im Bayerischen Landtag und Mitglied des Parlamentarischen Rates 1948/49 in Bonn schien Kroll dem Kreis der Gründer der geeignete Autor für eine revidierte Staats- und Gesellschaftskonzeption zu sein.

27 Vgl. Emil FranZEL, Die restaurativen Tendenzen der Epoche, in: NA 6 (1951), S. 529 ff.

28 Erich Fürst von Waldburg zu Zeil und Trauchtburg (1899-1953) gründete 1930 zusammen mit Fritz Gerlich die katholische Zeitschrift „Gerader Weg“, welche dem Nationalsozialismus gegenüber kritisch auftrat und 1933 eingestellt wurde; nach dessen Tod 1953 war sein Sohn, Georg Fürst von Waldburg zu Zeil und Trauchtburg, geb. 1928, Herausgeber des NA und stellvertretender Leiter, später auch Leiter der Akademie.

29 Gerhard Kroll (1919-1963), geb. in Breslau, Studium der Staatwissenschaften und Volkswirtschaft in Breslau, Wien und Berlin; nach Promotion und Volontariat 1929-1938 Studium der Philosophie und Religionswissenschaften; bis 1933 Mitglied der SPD; illegale Tätigkeit gegen den Nationalsozialismus, 1943-1945 Soldat; die Erfahrungen dieser Zeit führten ihn zu einem tief im Glauben verwurzelten Staats- und Sozialdenken (vgl. A.R.L. GuRLAND, Die CDU/CSU. Ursprünge und Entwicklung bis 1953, Frankfurt a.M 1980, S. 57 f.); 1945 in Bamberg Mitbegründer der CSU; Landrat in Staffelstein und Mitglied des Landesvorstandes der CSU (zu Krolls Einfluss auf das „ständische“ Organisationsprinzip der frühen CSU vgl. Alf MinTZEL, Die CSU, Opladen 1975, S. 194 ff.); MdL, Mitglied des Parlamentarischen Rats 1948/49; 1949-1951 Geschäftsführer des Deutschen Instituts zur Erforschung der nationalsozialistischen Zeit (seit 1952 Institut für Zeitgeschichte; vgl. Horst MöLlER, Das Institut und die Zeitgeschichtsforschung, in: DERS./Udo WENGST [Hg.]: 50 Jahre Institut für Zeitgeschichte. Eine Bilanz, München 1999, S. 13 ff.).

30 An die Leser, in: NA 6 (1951), S. 145.

31 Dr. Wolfgang Heilmann war Studienleiter der Abendländischen Akademie.

32 Zur Gründungsversammlung vgl. Abendländische Aktion. Zur Gründung am 25.8.1951 in München, in: NA 6 (1951), S. 508 ff. 
Entschieden verwirft das Manifest ${ }^{33}$ Parlamentarismus, Parteienwesen und plurale Interessenverbände (vgl. Anlage: Staatsaufbau). Der Volkssouveränität des Grundgesetzes wird der „organische Volksbegriff“ entgegengestellt, worin Kroll eine durch die natürliche Seinsordnung vorgegebene, „gesunde“ Gliederungsstruktur sieht. Das Verfassungsideal ist der Typus der gemischten Verfassung nach Aristoteles und Thomas, also eine Synthese von Monarchie, Aristokratie und Demokratie. Der natürliche Staats- und Gesellschaftsaufbau beruht auf zwei Säulen: (1.) der regionalen bzw. landständischen Gliederung und (2.) der leistungsgemeinschaftlichen bzw. berufsständischen Gliederung.

Gemäß der Regionalstruktur (1.) wählt das Volk Persönlichkeiten in den Gemeinderat; Parteien oder parteiähnliche Verbindungen stehen nicht zur Wahl. Der Gemeinderat wählt den Kreistag, der Kreistag den Bezirkstag, dieser den Landtag, der seinerseits die Abgeordneten der Volkskammer wählt. Diese fungiert als föderatives Organ der Länder. Die zweite Säule bildet die berufsständische Gliederung (2.). In ihr wirken Arbeitgeber und Arbeitnehmer (inklusive Gewerkschaften) einträchtig zusammen bei der Erstellung von Gütern und Dienstleistungen; diese Leistungsgemeinschaften verhindern vermeintlich die Aufspaltung der Gesellschaft in „Arbeit“ und „Kapital“, wie sie für die Marktwirtschaft typisch ist. Das wichtigste Vertretungsorgan des gegliederten Volkes ist der Senat, eine Art Oberhaus. Er wird gebildet zu 1/3 aus Mitgliedern der Volkskammer, zu 1/3 aus Vertretern der Ständekammer und zu 1/3 aus ,geachteten Persönlichkeiten“, die erstmals vom Staatsoberhaupt ernannt werden und in der Folgezeit ihre Mitglieder kooptieren. Ebenso werden die Vertreter der Berufsstände erstmalig vom Staatsoberhaupt ernannt, danach kooptieren auch sie ihren Mitgliederanteil, natürlich aus den Reihen

33 Gerhard Kroll, Grundlagen abendländischer Erneuerung. Das Manifest der Abendländischen Aktion (Sonderheft Neues Abendland), Augsburg 1951. Eine Vorarbeit ist die Studie Was ist der Staat?, München 1950, in der Kroll seine philosophisch-theologische Gesellschaftsdeutung offenlegt, die er wohl als Antwort auf seine parlamentarisch-politische Arbeit verfasst hat. Mit „Christliche Union: Bamberger Denkschrift zur Schaffung einer politischen Einheitsfront aller Christen Deutschlands", Schwäbisch Gmünd 1946 (konzipiert 1945), legte Kroll ein Vorläuferprogramm der CSU vor (vgl. Alf MinTZEL, Die CSU in Bayern, in: Richard STÖsS (Hg.): Parteienhandbuch, Bd. 2, Opladen 1983, S. 672), in dem er vor dem Hintergrund der „abendländischen Traditionen“ ein Konzept zum Neuaufbau der deutschen Staats-, Rechts-, Wirtschafts- und Kulturordnung sowie Grundsätze zur Sittlichkeit des Volkes und zum Verhältnis von Kirche und Staat entwirft. Die politisch-rechtliche Ordnungskonzeption ist eine Vorwegnahme seines Manifests, wobei Kroll mit seinen Vorbehalten gegenüber den Parteien und der liberalen Demokratie zurückhaltend ist. Auch seine Äußerungen im Parlamentarischen Rat wird man kaum als prinzipielle Kritik an der demokratischen Grundordnung verstehen können (vgl. die Redebeiträge Gerhard Krolls, aufgelistet im Sach- und Sprechregister zu den Verhandlungen des parlamentarischen Rates und seines Hauptausschusses 1948, Bonn [o.J.], S. $156 \mathrm{f}$.), wenngleich hier bereits im Zusammenhang mit seiner Vorliebe für das Zwei-Parteien-System organologische Ordnungsvorstellungen durchscheinen. 
der Berufsstände. Nur die Volkskammer wählt und entsendet ihre Vertreter in den Senat.

Der Staatspräsident wird seinerseits - auf Lebenszeit - in einem Konklave gewählt bzw. designiert, und zwar von einem ca. 40-köpfigen Wahlmännergremium, das aus Mitgliedern der Volkskammer und des Senats besteht. Kroll bevorzugt jedoch die Wahl eines Königs. Aufgrund der sakramentalen Herrscherweihe vermöge am sinnfälligsten ein König die in der göttlichen und natürlichen Schöpfungsordnung angelegte Ordnung und Macht des Staats zum Ausdruck zu bringen. Kroll zitiert den Grundsatz: „Le roi règne mais il ne gouverne pas " (Der König herrscht, aber er regiert nicht). ${ }^{34} \mathrm{Zu}$ den Befugnissen des Staatsoberhaupts gehören die Bestellung und Entlassung der Regierung; in Konfliktfällen obliegt ihm die Letztentscheidung.

Der Regierung schließlich kommt die Gesetzesinitiative zu. Kontrolliert werden die Regierung und ihre Gesetzgebung vom Senat, dem es auch obliegt, den Haushalt mit zu beraten. Im Falle einer Nichtübereinstimmung von Gesetzen mit dem Gemeinwohl ist der Senat befugt, Veto einzulegen und den Obersten Gerichtshof anzurufen. Diesem kommt die Aufgabe zu, Gesetzesvorhaben zu überprüfen und gegebenenfalls für unwirksam zu erklären. Maßstab der Überprüfung, so heißt es, ist das ,göttliche und natürliche Recht“.

Die Idee einer berufsständischen Ordnung war in den frühen 30er und den 50er Jahren unter den deutschen katholischen Theologen und Sozialwissenschaftlern weit verbreitet. Ihre Verfechter waren jedoch so weise, diese aus romantischem Gedankengut gespeiste Ordnungsidee lediglich als Leitbild zu titulieren; ${ }^{35}$ sie begriffen die subsidiäre Gliederung keineswegs als Gegensatz zur liberalen Demokratie. Krolls „Manifest“ geht weit hinter die Genossenschafts- und Ständeideen des 19. Jahrhunderts und gar der Enzyklika „Quadragesimo anno" zurück, indem es eine Ständestaatsordnung propagiert, die mit Elementen der mittelalterlichen Reichsidee und religiös-sakralen Vorstellungen angereichert wird. Mit seinen theologischen Exkursen hatte Kroll schon den Parlamentarischen Rat in Bonn beschäftigt. So wollte er - wie auch andere Abgeordnete - den Gottesbegriff im Grundgesetz stärker verankert wissen. Gegen diesen Antrag hatte Theodor Heuss entschieden Einspruch erhoben. Solche Legitimierungsstrategien provozierten nur theologische Auslegungsdebatten. ${ }^{36}$

34 Gerhard Kroll (wie Anm. 33), S. 71; die Fahne der Abendländischen Aktion war weiß, mit rotem Georgskreuz, in dessen Schnittpunkt der Doppelkopfadler auf goldenem Grund zu sehen war (vgl. Axel Schildt, wie Anm. 15, S. 54).

35 Vgl. Oswald von NelL-Breuning/Hermann SACHER, Wörterbuch der Politik, Heft I: Zur christlichen Gesellschaftslehre, Freiburg 1954, Sp. 79 ff.; Heft II: Zur christlichen Staatslehre, Freiburg 2. Aufl. 1957, Sp. 99 ff.; Oswald von NELL-BrEuning, Die soziale Enzyklika. Erläuterungen zum Weltrundschreiben Papst Pius' XI. über die gesellschaftliche Ordnung, Köln 2. Aufl. 1950.

36 In der 6. Plenarsitzung am 20. Oktober 1948, bemerkte Theodor Heuss: „Darüber, ob 
Es konnte kaum ausbleiben, dass Krolls revisionistisches „Manifest“ in der Öffentlichkeit Aufsehen erregte. Nicht unwesentlich trugen hierzu auch die flankierenden Stellungnahmen von Emil Franzel ${ }^{37}$ bei. In einem Artikel im „Neuen Abendland“ von 1952 bezeichnete Franzel Portugal als den „bestregierten Staat" Europas. ${ }^{38}$ „Es ist der christliche Freiheitsbegriff, der die Staatslehre Salazars durchdringt und sich in der Verfassung von 1933 spiegelt. Die Grundrechte werden auch in der portugiesischen Verfassung sorgfältig aufgezählt und in einer Reihe von Paragraphen verankert. Sie sind aber nicht Rechte des Individuums, das außerhalb der Schöpfungsordnung steht, sondern Rechte des Menschen, der von Natur aus, das heißt von der Schöpfung her gebunden ist".

So sei die portugiesische Verfassung im wesentlichen Ausfluss der „christlichen Staatslehre“, die eben den Menschen nur in seiner organischen Eingebundenheit in natürliche Einheiten - wie etwa die Familie - kenne; deren bevorzugte Stellung im Portugal der 50er Jahre drücke sich unter anderem darin aus, „dass nur das Familienoberhaupt das Wahlrecht ausübt“. 39

Von einem solchen Verständnis „,christlicher“ Staatstheorie her müssen konsequenterweise vorstaatliche Menschenrechte abgelehnt werden. Die Disposition über die Gewissens-, Meinungs- und Pressefreiheit steht einzig dem „rechtmäßigen Staatsoberhaupt“ als dem „Hüter der Gerechtigkeit und [...] Repräsentanten göttlicher Macht" zu; gegen deren Ausübung können keine individuellen Persönlichkeitsrechte geltend gemacht werden. Als Höhepunkt der Machtbefugnis steht dem Staat die Anwendung der Todesstrafe zu Gebote. In Krolls Manifest wird diese Haltung biblisch begründet. ${ }^{40}$

man eine theologische Formel mit hereinnimmt oder nicht, können wir miteinander reden. Aber von dorther kommt auch die Sorge, dabei Gott zu bemühen für die Unzulänglichkeiten, die Torheiten und die Missverständnisse, die auf Grund eines sehr menschlichen Werkes entstehen." Um der theologischen Position willen müsse man daher sehr vorsichtig sein, ,, diese sehr diesseitigen Werke zu stark im Metaphysischen verankern zu wollen, weil man sich selber dann in eine quasi Nichtverantwortung begibt" (Parlamentarischer Rat. Stenographische Berichte über die Plenarsitzungen, Bonn 1948/49, S.75 f. Vgl. Klaus TANNER, Gehört Gott in die Verfassung? Die Präambel des Grundgesetzes im Licht der europäischen Integration, in: Evangelische Kommentare 5 (1991), S. 260 ff.

37 Emil Franzel (1901-1976), geb. in Haan/Böhmen, Studium der Geschichte und Germanistik in Prag, München und Wien, nach der Promotion (1925) Journalist, bis 1934 Leiter des sozialdemokratischen Parteibildungswesens; 1934-1937 außenpolitischer Redakteur der Prager Zeitung „Sozialdemokrat“; Kontakte zur Zeitschrift „,Der christliche Ständestaat“, Verbindung zu Otto Strasser und dessen Wochenzeitschrift „Deutsche Revolution“, 1937 Austritt aus der SPD, Eintritt in die Sudetendeutsche Partei; nach Kriegsende und Vertreibung journalistische Tätigkeiten in Bayern (neben NA in der Deutschen Tagespost).

38 Emil Franzel, Portugal, der bestregierte Staat Europas, in: NA 7 (1952), S. 266 ff.

39 Emil Franzel (wie Anm. 38), S. 269.

40 Gerhard Kroll (wie Anm. 33), S. 54; vgl. auch Johannes PINSK, Vom Töten Gottes und von der Todesstrafe, in: NA 8 (1953), S. 65 ff. 


\section{Von der Abendländischen Aktion zur Abendländischen Akademie}

In einem dreiseitigen Artikel vom 10. August 1955 druckte „Der Spiegel“ Krolls Verfassungsentwurf ${ }^{41}$ auszugsweise ab und befand: „Das ,Manifest der Abendländischen Aktion“ und ihr ,Ordnungsbild“ lassen keinen Zweifel, dass die Erneuerungspläne darauf ausgehen, einen Teil der in den GrundgesetzArtikeln 1 bis 20 verbrieften Grundrechte abzuändern oder ganz aufzuheben. Dies, obgleich der Verfassungsgeber im Grundgesetz-Artikel 79 vorgeschrieben hat, jenes Verfassungsminimum sei für alle Zeiten unabänderlich.“ Den „Abendländern“ gehe es offensichtlich darum, die Verfassung der Bundesrepublik im Sinne eines klerikalen, autoritären und monarchistischen Ständestaates möglichst unauffällig umzuwandeln. ${ }^{42}$

So sehr das „Abendländische Manifest“ auch gegen die demokratische und rechtsstaatliche Verfassung der Bundesrepublik anschrieb, es hätte wohl kaum so nachhaltiges öffentliches Interesse geweckt, wenn es bloß das Werk eines relativ unbekannten, kleinen Aktionskreises, bestehend aus Professoren und Publizisten, gewesen wäre. Zum Politikum konnte das Manifest erst werden, wenn ihm die geistige Mitautorenschaft eines prominenteren Kreises bescheinigt werden konnte. Diesen fanden die Spiegelredakteure in der Abendländischen Akademie, die ihre Jahrestagungen seit 1952 in der bayerischen Bischofsstadt Eichstätt abhielt. ${ }^{43}$ Die Abendländische Akademie war mit dem Ziel gegründet worden, den abendländisch-europäischen Gedanken in seiner kulturellen Vielfalt tiefer zu durchdringen und ihm national und international größere Resonanz zu verschaffen. Die Gemeinschaft der abendländischen Völker sollte - von einer religiösen Sittenordnung getragen - die diesseitige

41 Vgl. Das Ordnungsbild der Abendländischen Aktion, hg. vom Deutschen Landesvorstand der Abendländischen Aktion, München 1952 (2. Aufl. 1953), eine leicht modifizierte Zusammenfassung der Ordnungsintentionen des „Abendländischen Manifests“.

42 Der Spiegel vom 10. August 1955, S. 12 ff.; vgl. ferner Der Spiegel vom 24. August 1955, S. 5 f.; 31. August 1955, S. 4 ff.; 15. Februar 1956, S. 18 f.; ferner Immanuel GEISS, Auf dem Wege zum „Neuen Abendland”, in: Die Neue Gesellschaft, 2/Heft 6 (1955), S. 41 ff.

43 Vorsitzender des Vorstands der Akademie und Mitglied der Akademieleitung von 1952 bis 1956 war Friedrich August Freiherr von der Heydte (1907-1994), geb. in München, Studium der Rechtswissenschaften, seit 1951 Professor für Staatsrecht an der Universität Mainz, seit 1954 an der Universität Würzburg. Von der Heydte vertrat die Bundesregierung vor dem Bundesverfassungsgericht zur Frage der Parteienfinanzierung durch steuerbegünstigte Spenden; seit 1947 Mitglied der CSU, von 1948-1956 Mitglied des Zentralkomitees der deutschen Katholiken. Neben Stählin, Asmussen, Heilmann gehörte auch Dr. Karl Bernhard Ritter, Dekan in Marburg, als Beiratsmitglied zu den evangelischen Vertretern der Abendländischen Akademie, sowie als Referenten die Juristen Dr. Hans Dombois, Fulda, und Professor Ulrich Scheuner, Bonn; zu den evangelischen Mitgliedern vgl. Axel SCHILDT, Ökumene wider den Liberalismus. Zum politischen Engagement konservativer protestantischer Theologen im Umkreis der Abendländischen Akademie, in: Thomas SAUER (Hg.), Katholiken und Protestanten in den Aufbaujahren der Bundesrepublik, Stuttgart 2000, S. 187 ff. 
Welt durchdringen und im Sinne einer organischen und föderativ gegliederten Ordnung prägen. ${ }^{44}$ Mag dabei auch die Absicht mitgewirkt haben, die Abendländische Aktion und ihr „Manifest“ etwas aus der Schusslinie zu ziehen, so wird man doch feststellen müssen, dass eine deutlicher vernehmbare Distanzierung der Akademie von der Aktion und ihrem „Manifest“ erst nach den zum Teil äußerst kritischen Berichten und Kommentaren verschiedener Presseorgane einsetzte.

Neben Auszügen aus dem „Abendländischen Manifest“ druckte das Hamburger Magazin in seinem Artikel auch eine Liste der prominenten Mitglieder der „Abendländischen Akademie“ und ihrer Organe ab, die einem „Who is Who" des deutschen und europäischen Konservatismus glich. Der Tenor des Berichts lautete: Namhafte Politiker, Kirchenvertreter und süddeutscher Adel finden sich zusammen, um die Errichtung einer übernationalen bzw. völkischen Reichsordnung zu begründen. ${ }^{45}$

Die Liste ist aufgeteilt nach Vertretern des adeligen, bürgerlichen und geistlichen Standes. Genannt werden:

\section{Adelige:}

Eberhard Fürst von Urach;

Georg Fürst von Waldburg zu Zeil und Trauchtburg, Verleger der Zeitschrift „Neues Abendland“, stellvertretender Vorsitzender der Akademie;

Elimar Freiherr von Fürstenberg, ehemals MdB, Bayernpartei;

Dr. Friedrich August Freiherr von der Heydte, Professor für Staats- und Völkerrecht in Würzburg, Vorsitzender der Akademie;

Ritter Georg von Gaupp-Berghausen, Generalsekretär der Akademie;

Dr. Heinrich von Brentano, Bundesaußenminister, CDU;

Dr. Hans-Joachim von Merkatz, Bundesratsminister, DP;46

Dr. Rudolf Lodgman von Auen, Vorsitzender des Verbandes der Landsmannschaften;

44 Vgl. Abendländische Akademie. Wesen, Ziel und Organisation, München 1953, S. 3 f. 45 Aufgehängt war der Bericht an der ersten öffentlichen Rede von Heinrich von Brentano als Außenminister anlässlich der St.-Ulrichs-Festwoche in Augsburg zur Tausendjahrfeier der Schlacht auf dem Lechfeld; vgl. Heinrich von BRENTANO, „Innere und äußere Einheit Europas bringt Frieden. Die Bedrohung des Abendlandes - Lehren aus der Vergangenheit für die Gegenwart", in: Bulletin des Presse- und Informationsamtes der Bundesregierung Nr. 128, vom 14. Juli 1955, S. 1069 f.; zur Verwendung des Abendlandbegriffs bei Adenauer vgl. Anselm DOERING-MANTEUfFel, Rheinischer Katholik im Kalten Krieg. Das „christliche Europa“ in der Weltsicht Konrad Adenauers, in: Martin Greschat/Wilfried LOTH (Hg.), Die Christen und die Entstehung der Europäischen Gemeinschaft, Stuttgart 1994, S. 237 ff.

46 Vgl. die Ausführungen von Joachim von Merkatz, Richard Jaeger u.a anlässlich einer Monarchiedebatte im Deutschen Bundestag, 166. Sitzung vom 10. Oktober 1951, in: Verhandlungen des Deutschen Bundestages. I. Wahlperiode 1949, Stenographische Berichte Bd. 9, Bonn 1951 S. 6789 ff.; dazu NA 6 (1951), S. 637 ff. 
Hasso von Manteuffel, Panzer-General a.D. und FDP-MdB;

Walter von Keudell, Reichsminister a.D.

Bürgerliche:

Professor Dr. Theodor Oberländer, Bundesvertriebenenminister;

Dr. Franz-Joseph Wuermeling, Bundesfamilienminister, CDU;

Heinrich Hellwege, Ministerpräsident von Niedersachsen;

Dr. Friedrich Holzapfel, Gesandter in Bern;

Professor Dr. Josef Süsterhenn, Präsident des Verfassungsgerichtshof von

Rheinland-Pfalz, ehem. CDU-Abgeordneter im Parlamentarischen Rat;

Dr. Richard Jaeger, Vizepräsident des Bundestages, CSU, früherer Oberbürgermeister von Eichstätt;

Hans Schuberth, Bundespostminister a.D., CSU-MdB;

Dr. Hermann Pünder, CDU-MdB, früherer Oberdirektor der Frankfurter

Wirtschaftsverwaltung (Bizone/Trizone);

Dr. Alois Hundhammer, Präsident des bayerischen Landtags a.D., CSU

Geistliche:

Lorenz Kardinal Jaeger, Erzbischof von Paderborn;

Joseph Schröffer, Bischof von Eichstätt;

Hugo Lang, OSB, Abt von St. Bonifaz und Andechs;

Basilius Ebel, OSB, Abt von Maria Laach;

Prälat Michael Schmaus, Dogmatikprofessor an der Universität München;

Wilhelm Stählin, ehemaliger evangelischer Landesbischof von Oldenburg; ${ }^{47}$

Dr. Hans Asmussen, Probst der Evangelischen Kirche in Kiel. ${ }^{48}$

Regelmäßige Tagungsteilnehmer ${ }^{49}$ waren außerdem

Otto von Habsburg, Präsident des Europäischen Dokumentationszentrums; Prinz Bernhard von Preußen.

47 Wilhelm Stählin (1883-1975), geb. in Gunzenhausen/Franken, nach Theologiestudium und Ordination verschiedene Pfarrstellen in Bayern; 1925 Professor für praktische Theologie in Münster, 1945-1952 Bischof der Ev.-Luth. Kirche in Oldenburg, lebte danach in Rimsting/ Chiemsee.

48 Hans Christian Asmussen (1898-1968), geb. in Flensburg, 1925-1932 Pfarrer, bis 1935 Leiter der Theologischen Abteilung des Präsidiums der Bekenntnissynode, 1934 Mitautor der Barmer Theologischen Erklärung, 1935-1941 in der Kirchenleitung der Bekennenden Kirche, 1949-1955 Propst in Kiel (Materialien zur Abendländischen Akademie im Archiv für Christlich-Demokratische Politik der Konrad-Adenauer-Stiftung, Sankt Augustin).

49 Teilnehmer der Tagungen der Abendländischen Akademie in Eichstätt waren ferner der Historiker Ernst Deuerlein, der Philosoph Alois Dempf, der Schriftsteller Werner Bergengruen. 
Der vom „Spiegel“" erhobene Vorwurf der Verfassungsfeindlichkeit des "Abendländischen Manifests" wurde von zahlreichen Zeitungen und Zeitschriften der Bundesrepublik und der Sowjetzone im Laufe des Jahres 1955 aufgegriffen. Die „Frankfurter Allgemeine Zeitung“ titelte: „Nebel über dem Abendland". ${ }^{50}$ Am 7. Dezember 1955 fragte der SPD-Abgeordnete Helmut Schmidt (Hamburg) in einer Bundestagsfragestunde, ob die Regierung die „Zugehörigkeit von Kabinettsmitgliedern bei der Abendländischen Akademie" [billige, der],,verfassungsfeindliche Äußerungen" nachgesagt würden. Bundesinnenminister Gerhard Schröder kündigte eine umfassende „Überprüfung" an, ohne dass allerdings eine offizielle Reaktion folgte. ${ }^{51}$

Der Vorsitzende der Abendländischen Akademie, der Staats- und Völkerrechtler Friedrich August Freiherr von der Heydte, veröffentlichte in der „Deutschen Tagespost“ im Februar und März 1956 zwei eingehende Darstellungen unter der Überschrift: „Fälscher am Werk “52. Schon auf einer Tagung im Jahr 1954 hatte sich von der Heydte im Beisein des Präsidenten des Bundesverfassungsgerichts, Joseph Wintrich, gegen Vorwürfe der Verfassungsfeindlichkeit

50 Vgl. Hansjakob Stehle, FAZ vom 9. Februar 1956. Demgegenüber verteidigte Paul Wilhelm WENGER, Jakobinische Gespensterjagd. Zum Kesseltreiben gegen die Abendländische Akademie, in: Rheinischer Merkur vom 10. Februar 1956, die Abendländische Akademie gegenüber den Angriffen der „formaldemokratische(n) Kapitolswächter“ der „Funktionsdemokratie“. Diesen gehe es darum, Außenminister von Brentano „zur Strecke zu bringen“; die Vorwürfe würden wohl auf Dr. Kroll und die Abendländische Aktion zutreffen, die Abendländische Akademie jedoch sei eine „lose Konfiguration“ und nicht mit Einzelstimmen gleichzusetzen.

51 Vgl. Verhandlungen des Deutschen Bundestages, 2. Wahlperiode 1953. Stenographische Berichte, Bd. 27, Bonn 1955, S. 6196 (116. Sitzung vom 7. Dezember 1955); Schröder bestritt in seiner Antwort einen formellen und materiellen Zusammenhang zwischen der Abendländischen Akademie und der Abendländischen Aktion - eine Differenzierung, die Schmidt in Zweifel zog, weil 1. der stellvertretende Generalsekretär der Abendländischen Akademie im August 1955 öffentlich erklärt habe, dass die Aufgaben der Abendländischen Aktion seit zwei Jahren von der Abendländischen Akademie fortgeführt würden, und 2. die Abendländische Aktion und Abendländische Akademie ,aus der gleichen Quelle finanziert worden“ seien „,und weiterhin finanziert werden“. Helmut Schmidt zitierte als Beleg ,verfassungsfeindlicher Äußerungen“, die im Kreise „sowohl der Abendländischen Aktion als auch der Abendländischen Akademie“" getätigt worden seien - ohne Quellenangabe - aus Gerhard KROLL, Das Manifest der Abendländischen Aktion (wie Anm. 33), S. 66: „Als Träger der Regierungsverantwortung kann man nicht gleichzeitig Gott in seinem Gewissen verantwortlich sein und die Gesetze aus der Hand Dritter empfangen oder, wie es in der parlamentarischen Demokratie üblich ist, sogar noch vom Vertrauen des Parlaments abhängig sein.“ Bundesminister Schröder erwiderte: „Eine bemerkenswerte Stelle, die Sie zitiert haben, Herr Kollege. Ich möchte sagen, unsere Überprüfung wird umfassend sein.“ Nach einer Agentur-Meldung des Bayerischen Rundfunks vom 25. Oktober 1956 wurde ein staatsanwaltschaftliches Untersuchungsverfahren „mangels Verdachts“ eingestellt. Nach einem Bericht des Spiegel, Nr. 45/1956, heißt es, die Begründung berufe sich darauf, dass es sich beim Ordnungsbild der „Abendländischen Aktion“ „offenkundig um wirklichkeitsfremde Vorschläge“ gehandelt habe, bei der „Abendländischen Akademie“ hingegen um „hochgeachtete Persönlichkeiten, an deren Verfassungstreue kein Zweifel gesetzt werden könne“.

52 Deutsche Tagespost vom 29. Februar und 12. März 1956. 
mit der ironischen Wendung verwahrt: „Was auf den Tagungen der ,Abendländischen Akademie " geschieht, ist konstruktiver Verfassungsschutz."53

Was geschah auf den Tagungen der Abendländischen Akademie? In ihrer Ausgabe von 1955/56 bemühte sich die Freiburger „Herder-Korrespondenz“ in einem Hintergrundbericht, die Zielsetzung der Eichstätter Tagungen vom „Manifest“ Gerhard Krolls abzugrenzen. Dieses enthalte lediglich dessen ,private Staatsutopie“, die nicht mit den Intentionen der heutigen Abendländischen Akademie ,zusammengemischt“ werden dürfe. Im übrigen sei Dr. Kroll aus der Schriftleitung des Neuen Abendlands und aus der Abendländischen Aktion ausgeschieden. ${ }^{54}$ Allerdings hatten Kroll, Franzel ${ }^{55}$ und andere Mitglieder der „Aktion“ auch bei den Akademietagungen zwischen 1952 und 1956 als Referenten und Debattenredner mitgewirkt, soweit erkennbar jedoch monarchistische und dezidiert ständestaatliche Vorstellungen nicht mehr vertreten. ${ }^{56}$

Generell ist festzustellen, dass in den offenen Foren in Eichstätt berufsständische Ideen und antiparlamentarische Ressentiments keineswegs ungeteilt Beifall fanden. ${ }^{57}$ So verwarf der evangelische Staatsrechtler Hans Dombois aus Fulda die Ständeidee als „Ideologie“ und „Utopie““58 Die gesamte euro-

53 Der Spiegel vom 10. August 1955, S. 14.

54 Vgl. Herder-Korrespondenz 10 (1955/56), S. 492. - Am 22. Februar 1956 war die Akademie mit einem Pressebericht (,Ist die Abendländische Akademie verfassungsfeindlich?“) an die Öffentlichkeit getreten. Am 9. März 1956 äußerten sich in einer Pressekonferenz in Bonn der Geschäftsführende Vorsitzende der Akademie, Georg Fürst von Waldburg-Zeil, Bundesminister von Merkatz, Bundestagsvizepräsident Jaeger und Ministerpräsident a. D. Steltzer zu den erhobenen Vorwürfen gegen die Akademie (vgl. Herder-Korrespondenz, ebd.). Am 24. Februar 1956 trat Freiherr von der Heydte als Akademievorsitzender zurück, da die Abendländische Akademie ,,zur Zielscheibe linkstendierender Kräfte geworden“ sei. Um „,dieser Hetze mit genügendem Nachdruck und entsprechender Wirkung entgegentreten zu können“, hätte es der „Unterstützung durch Gesinnungsfreunde als auch ausreichender Zeit bedurft. [...] Ich hatte weder das eine noch das andere." (Schreiben im Diözesan-Archiv Eichstätt, zit. nach Axel SCHILDT, wie Anm. 15, S. 70 f.).

55 Emil Franzel bedauerte, dass man nach dem großen Wahlsieg der CDU/CSU 1953 ,diese Bewegung nicht durchdrungen (hatte) mit genügend viel konservativem Geist“, weil „,zuwenig konservative Männer da waren“ (Konservative Haltung in der politischen Existenz. Vorträge und Gespräche der 5. Jahrestagung der Abendländischen Akademie 1956, München [1956], S. 74, 77).

56 Die erste Eichstätter Tagung widmete sich dem Thema ,Werte und Formen im Abendland. Jahrestagung der Abendländischen Akademie vom 6.-10. August 1952 in Eichstätt“ (hektographiertes Typoskript); einzelne Beiträge wurden auch im NA abgedruckt.

57 Erwähnenswert ist die sozial-, arbeits- und vermögenspolitische Programmatik der Gruppe um das NA, die in den meisten Darstellungen über das NA keine Erwähnung findet; vgl. die Artikel von Gerhard Kroll in „Die Neue Ordnung “, 10 (1956); 11 (1957), 12 (1958), 13 (1959); ferner Damian van MELIS, Europapolitik oder Abendlandideologie? Die Dominikanerzeitschrift Neue Ordnung in den ersten Jahrzehnten der BRD, in: Thomas SAUER (Hg.): Katholiken und Protestanten in den Aufbaujahren der Bundesrepublik, Stuttgart 2000, S. 170 ff.; vgl. auch unten Anmerkung 67.

58 Vgl. Hans DomboIs, Die Vernichtung der Freiheit im Totalitarismus, in: Der Mensch und die Freiheit. Vorträge und Gespräche der Jahrestagung der Abendländischen Akademie, München (1953), S. 88 ff.; vgl. ferner die Aussprache des 4. Tages, ebd. S. 141 ff.; DERS., 
päische Verfassungsentwicklung laufe heute - 1953 - auf eine Ausweitung der parlamentarischen Demokratie hinaus, wie dies z.B. in England zu beobachten sei; ebenso sei auch schon im Landtag von München ein Antrag auf Abschaffung des Bayerischen Senats gestellt worden. Etliche Politiker und Juristen wie der Präsident des Verfassungsgerichts von Rheinland-Pfalz, Adolf Süsterhenn, sahen im Konservatismus eher eine politische Theorie, die die Gesinnung betrifft, die jedoch einer konstruktiven politisch-parlamentarischen und verfassungsstaatlichen Arbeit keineswegs widerspreche. Im übrigen seien Verfassungstext und Verfassungswirklichkeit, so Süsterhenn, streng zu unterscheiden. ${ }^{59}$

Konterkariert wurden solche Unterscheidungen zwischen Theorie und Politik durch zahlreiche Referenten, die versuchten, ihre Ordnungsvorstellungen von ontologischen Ideen her zu deduzieren - wie etwa Gustav Gundlach S.J., Professor an der Päpstlichen Universität Gregoriana Rom und Sozialberater Pius' XI. und Pius' XII. Für Gundlach ist die „richtige Machtordnung“ von der göttlichen Schöpfungsordnung nicht zu trennen. So verurteilt der Jesuit nicht nur Sozialismus, Idealismus, philosophischen Existentialismus und Liberalismus als Systeme; vielmehr stehe auch die konkrete liberale Verfassungsund Gewaltenteilungslehre in einem objektiven Widerspruch zur göttlichen Weltordnung. ${ }^{60}$ Auch wenn christliche Prinzipien geschichts- und gestaltungs-

Menschenrechte und moderner Staat, Frankfurt 1948; DERS., Naturrecht und christliche Existenz, Kassel 1952; DERS./Erwin WILKENS (Hg.), Macht und Recht. Beiträge zur lutherischen Staatslehre der Gegenwart, Berlin 1956.

59 Vgl. die Aussprache des 3. Tages über das Subsidiaritätsprinzip (Referent: A. Süsterhenn), in: Staat, Volk, übernationale Ordnung. Vorträge und Gespräche der 3. Jahrestagung der Abendländischen Akademie 1954, S. 116 ff. - Dr. Adolf Süsterhenn (1905-1974), geb. in Köln, nach Jurastudium, Promotion und Referendariat 1932-1946 Rechtsanwalt in Köln und Unkel/Rhein, Zentrums-Stadtverordneter in Köln; 1946 Vorsitzender der vorbereitenden Verfassungskommission für Rheinland Pfalz; Mitglied des Parlamentarischen Rates 1948/49 (stellvertretender Vorsitzender der CDU/CSU-Fraktion); 1947-1951 Justiz- und Kultusminister in Rheinland-Pfalz; 1951-1961 Präsident des Oberverwaltungsgerichts und des Verfassungsgerichtshofs in Rheinland-Pfalz; 1961-1969 MdB; seit 1951 Honorarprofessor für Staatslehre an der Hochschule für Verwaltungswissenschaften in Speyer. - Referent und Debattenredner der Eichstätter Tagungen war auch Winfried MARTINI, Verfasser von: Das Ende aller Sicherheit. Eine Kritik des Westens, Stuttgart 1954.

$60 \mathrm{Vgl}$. Gustav GuNDLACH, Konservative Haltung in der politischen Existenz, in: Konservative Haltung, S. 27 ff., ferner in Gustav GundLaCH, Die Ordnung der Gesellschaft, Bd. 1, Köln 1964, S. 570 ff.; vgl. ebd., Bd. 2, S. 174 f. die Kritik Gundlachs an Jacques Maritains liberal-christlichen Personalismusbegriff. - Vgl. dagegen das Referat des Frankfurter Philosophiegeschichtlers Johannes HIRSCHBERGER (Beiratsmitglied der Abendländischen Akademie): Die autonome Freiheit. Die Entstehung des neuzeitlichen Freiheitsbewußtseins, auf der 2. Jahrestagung 1953, in: Der Mensch und seine Freiheit. Vorträge und Gespräche der Jahrestagung der Abendländischen Akademie, München (1953), S. 59 ff., wo der Referent - mit deutlicher Kritik an der Neuscholastik - die Vielfalt und Breite der „großen abendländisch-christlichen Tradition“, ihren Humanismus und ihre „ethische Autonomie“ in Erinnerung ruft und die verengte Kant-Interpretation im Katholizismus kritisiert. Menschliche Freiheit und Verantwortung als Aufgabe werden dabei als Produkte der abendländischen Geisteswelt gewürdigt. Der Ver- 
offen seien, beinhalteten sie doch „,seinssichere“ Normen, an die das menschliche Gewissen gebunden sei. Gundlachs Bild der „geprägten Persönlichkeit“ in überschaubaren Gemeinschaften stieß beim Gros der Tagungsteilnehmer von 1956 offenbar auf Resonanz. Der Politologe Paul Noack, der für die „Frankfurter Allgemeine Zeitung“ berichtete, bescheinigt vor allem den Referenten Gundlach und Stählin hohes Niveau, registrierte aber zugleich eine Flucht in „glanzvolle Formulierungen“, in denen man sich bisweilen erschöpft habe. Der Berichterstatter bemerkt: „Das, was sich in den Veranstaltungen und Empfängen zeigte, rechtfertigte nicht das Pathos, mit dem man gegen die ,Abendländische Akademie' nach dem Bundesverfassungsgericht gerufen hat. Gewiss erscheint manches zwiespältig. Verfassungsgefährdendes haben wir aber nicht gefunden."

Was die Rolle der Adeligen angeht, so anerkennt er deren „Ideen [...] und die Überzeugungskraft“ und resümiert: „Man widerstand der Gefahr monarchistischer Plädoyers." Auffällig sei jedoch die einseitige Konzentration vieler Referenten und Debattenredner auf antiquiertes Autoritäts-, Hierarchie- und Elitedenken in den Akademiebeiträgen - ein Umstand, den Noack schichtenund standortspezifisch zu erklären sucht. Den Teilnehmerkreis vereine „das Kontra zur modernen Industrie- und Maschinenwelt““. Im übrigen bewirke „die traditionsgebundene Atmosphäre" von Eichstätt, dass gravierende politische, rechtliche und gesellschaftliche Fragen an die Peripherie gedrängt würden. So resümiert Noack, dass das Echo der Akademiereferate wohl ein anderes wäre, wenn diese „zwischen den Schloten und Hochöfen des Ruhrgebiets vorgetragen würden". 61

Dass die Abendländische Akademie jedoch auch dezidierte Kritiker des konservativen Verfassungsdenkens zu Wort kommen ließ, demonstrieren neben Dombois - u.a. die Referate des evangelischen Staatsrechtlers Ulrich Scheuner. Was Scheuner als Grundelemente „abendländisch-christlicher Überlieferung " kennzeichnet, sind vor allem das humanistische Bildungsideal und das Bekenntnis zu den Menschenrechten. Den Abendlandgedanken deutet Scheuner vor allem im Hinblick auf die europäische Rechtskultur und Verfassungsgeschichte; romantischen und traditionalistischen Ordnungsvorstellungen erteilt er eine klare Absage. Sicher sei der Staat eine menschen- und generationenübergreifende Existenzform, gleichwohl vollzögen sich Entscheidungen stets im Rahmen pluralistischer Willensbildung. ${ }^{62}$

gleich der Referate von Gundlach und Hirschberger ist aufschlussreich hinsichtlich der Positionen eines liberalen und konservativen katholischen Denkstils.

61 Ulrich NOACK, ,Sämänner, umschwirrt von Fragezeichen. Nach der Jahrestagung der Abendländischen Akademie“, in: Frankfurter Allgemeine Zeitung vom 22. Juni 1956.

62 Ulrich Scheuner, Das Verhältnis von Staat und Volk, in: Staat, Volk, übernationale Ordnung. Vorträge und Gespräche der 3. Jahrestagung der Abendländischen Akademie, Mün- 
Dass solche Positionen in den Eichstätter Akademietagungen zwar möglich, aber nicht unbedingt mehrheitsfähig waren, bemerkt der Berichterstatter der „Süddeutschen Zeitung“, Burghard Freudenfeld. Er kommentiert die Tagung von 1955:

„Unverhüllt war die Diagnose Deutschlands, die Ulrich Scheuner, der Bonner Staatsrechtler [...] anstellte, als er die Möglichkeiten einer allgemeinen Sinngebung der gegenwärtigen deutschen Lage ebenso entschieden bestritt wie die verbreitete Ansicht, dass das große Schweigen bereits ein Vergessen sei. Das ,Reich “ und die ,Mittlerrolle zwischen West und Ost ${ }^{\text {- }}$ - das bleibe ebenso unabwendbar wie die Vorstellung vom, Glacis'. Er empfahl Geduld und Anpassung und vor allem auch Vorsicht mit dem Vorwurf der Restauration, die ja immerhin den Vorteil einer Abkehr von der ewigen Unruhe von Wunschträumen in sich berge. Und dann endlich der Hinweis, dass zum Christentum und zur humanistischen Bildung auch der moderne Staat der Menschenrechte und bürgerlichen Freiheiten gehört - eine Selbstverständlichkeit, aber doch notwendig in diesem Kreise, der allzu leicht Gefahr läuft, um der Einheit der Anschauung willen seit 400 Jahren nur noch Verfall zu diagnostizieren."

Es scheine künftig notwendig, sowohl den Kreis der Themen wie der Referenten zu erweitern. Diagnosen seien nun über Gebühr strapaziert, und doch, so konzediert Freudenfeld, wäre es ,ein empfindlicher Verlust, wenn die Akademie als Partner eines solchen Gesprächs ausfiele“. ${ }^{63}$ Die letzte Jahrestagung dieser Art fand mit 250 Teilnehmern 1956 im Spiegelsaal der Eichstätter Residenz statt; zwei Jahre später stellte die Zeitschrift „Neues Abendland“ ihr Erscheinen ein. Die Eichstätter Jahrestagungen wurden für die nächsten Jahre ausgesetzt - eine Folge der „Pressekampagne“. 64

chen 1954, S. 30 ff.; DERS., Der Beitrag Deutschlands, in: Das Abendland im Spiegel seiner Nationen. Vorträge und Gespräche der 4. Jahrestagung der Abendländischen Akademie, München 1955, S. 58 ff.; vgl. DERS., Die deutsche Bewußtseinskrise, in: NA 10 (1955), S. 333 ff.

63 Burghard FreudENFELD, „Beschwörung des Abendlandes“, Süddeutsche Zeitung vom 23. April 1955.

64 In seiner Eröffnung der Jahrestagung ging Georg Fürst von Waldburg zu Zeil (Aufgabe und bisherige Arbeit der Akademie, in: Konservative Haltung, S. 9 ff.) ausführlich auf die politischen und publizistischen Angriffe ein und grenzte noch einmal den Akademieauftrag von der Abendländischen Aktion ab. - Im November 1958 fand in München eine Mitgliederversammlung der Abendländischen Akademie statt. Die interkonfessionelle Ausrichtung der Akademie wurde unterstrichen durch neue Mitglieder wie Karl Forster, Direktor der Katholischen Akademie in Bayern, und Hans Schomerus, Leiter der Evangelischen Akademie in Baden. Als Vorsitzender, stellvertretender Vorsitzender und Generalsekretär wurden Walter von Keudell, Dr. Hans Hutter, Oberbürgermeister von Eichstätt, und Alois Graf Waldburg-Zeil berufen (vgl. Axel SCHILDT, wie Anm. 15, S. 77). Zu Karl Forster und der Katholischen Akademie in Bayern vgl. auch meinen Beitrag in diesem Band über „Christliche Sozialethik und Christliche Demokratie“. 
Der Oldenburger Altbischof Wilhelm Stählin widmet in seinen Erinnerungen 1968 den Eichstätter Akademietagungen ein längeres Kapitel. Er lobt den offenen Geist und die ästhetischen Reize der Bischofsstadt Eichstätt sowie das literarische und künstlerische Beiprogramm der Akademietagungen. ${ }^{65}$ Vor allem hebt er den ökumenischen Charakter der Treffen hervor; um so mehr bedauert Stählin, dass es ihm nicht gelungen sei, ,weitere evangelische Kreise und führende Kirchenmänner für diese Arbeitsgemeinschaft zu gewinnen“. „Fast immer und überall“ sei er auf eine ,argwöhnische Zurückhaltung“" gestoßen, auf ein „kaum verhehltes Misstrauen, zu dem hier wirklich kein Anlass" bestanden habe. Dieses Scheitern führt er vor allem auf die ,im Interesse der Polemik gern verwechselt(e)“ „Abendländische Akademie“ mit „Abendländischer Aktion“ in der Presse zurück; von der „Aktion“ distanziert sich der Geistliche hier ausdrücklich. Die Nachfolgetagungen, die - mit wesentlich geänderter Konzeption - Anfang der 60er Jahre wieder in Eichstätt stattfanden, hätten jedoch nicht mehr das frühere Niveau gehabt. Außerdem habe es den späteren Referenten an einer tieferen Beziehung zum „Abendländischen Akademiegedanken“ gemangelt. Stählin veranschaulicht: „Als einer der Redner sich zu der Behauptung verstieg, für das Recht sei nur die Meinung des (souveränen) Volkes maßgebend, habe ich „Pfui' gerufen“ - „leider ohne dass es der Vortragende hörte."

Die Kritik des Bischofs kann wohl auch im Sinne einer - von ihm missbilligten - liberal-demokratischen Modifizierung des abendländischen Rechtsgedankens durch den betreffenden Referenten verstanden werden. ${ }^{66}$

\section{Zusammenfassung und Ergebnisse}

In meinem Referat habe ich einen Ausschnitt der konservativen Kulturkritik der frühen Bundesrepublik geboten. Die Vision der Herausgeber und Redakteure des „Neuen Abendlands“, die sich im „Manifest der Abendländischen Aktion“ von 1951 verdichtete, verstand sich als Kritik an der bundesrepublikanischen Verfassung. Die aus der „Aktion“ hervorgegangenen Eichstätter Akademietagungen mühten sich, den revisionistischen Charakter des Manifestes, näherhin dessen aristokratisch-ständestaatliche Intentionen zu mildern. So öffnete sich der Kreis der Referenten vorsichtig und ließ auch liberale Rechts- und Verfassungsinterpreten

65 Vgl. Wilhelm StÄHLIN, Via Vitae. Lebenserinnerungen, Kassel 1968, S. 713 ff.; besonders eindrücklich war für Stählin die Aufführung des Ludus de Antichristo (eines Spiels aus der Zeit Kaiser Barbarossas) durch das Delphische Institut Mainz vor dem barocken Westportal des Eichstätter Domes 1954, zu dem Stählin die Einführung schrieb (vgl. STÄHLIN, Das Spiel vom Antichrist, in: Staat, Volk, übernationale Ordnung, München 1954, S. 100 ff.); ferner mit Anmerkungen und Literatur in: NA 10/1955, S. 67 ff.)

66 Die Eichstätter Akademietagungen wurden für fünf Jahre unterbrochen. 1960 fanden je eine Veranstaltung in Bensberg und in Mainz statt. 1961 folgte wieder eine Tagung in Eichstätt, 
zu Wort kommen. Verschiedene Entwürfe von „Abendland“ in staatsrechtlicher und darüber hinausgehend geistig-kultureller Hinsicht wurden diskutiert, wobei die Akzeptanz des pluralistischen und demokratischen Selbstverständnisses der Gesellschaft gegenüber dem Ideal ständischer Gliederung mehr und mehr Platz griff. Der Wunsch, diese Ordnung im Sinne christlich-konservativer und christlich-sozialer Werte mitzugestalten, schob die Ansätze einer konservativen „Revision“ des Grundgesetzes beiseite - doch ohne ausdrücklich und öffentlichkeitswirksam mit ihnen zu brechen. Daher und zumal wegen der personellen Kontinuität von „Aktion“ und „Akademie“ (Kroll, Franzel) konnte eine klare Distanzierung von romantisch-restaurativem Gedankengut letztlich nicht gelingen. Die Verfassungswirklichkeit, die politische Theorie und selbst die katholische Staatslehre sind schließlich über diese Form konservativen Ordnungsdenkens hinweggeschritten.

Den Übergangscharakter des Abendlandgedankens heben neben Axel Schildt auch Guido Müller und Vanessa Plichta als wesentliches Ergebnis ihrer Untersuchung hervor. Müller/Plichta sehen in den späten 50er und frühen 60er Jahren eine „,ideen- und gesellschaftsgeschichtliche Umbruchzeit“, in der „Altes" abgelöst und ,überkommene“ Denkhaltungen wie die ältere Europa-Konzeption, d.h. die Vorstellung vom „Abendland“, zurückgedrängt wurden. Die unterschiedlichen, teilweise gar gegensätzlichen verfassungstheoretischen Aussagen der „Abendländer“ und deren theoretische und konfessionellen Hintergründe (katholisches Naturrecht, evangelische Positionen) finden sich in dieser Darstellung, die sich primär den international-europäischen Ideen widmet, praktisch nicht. ${ }^{67}$ Differenzierter ist wohl die Analyse von Axel Schildt,

dokumentiert in: Pluralismus, Toleranz und Christenheit. Beiträge von Hans SCHOMERuS u.a., Abendländische Akademie, Nürnberg 1961. Die Mainzer Tagung und die Jahrestagung in Eichstätt 1962 sind wiedergegeben in: Das europäische Erbe in der heutigen Welt. Beiträge von Raimondo PANIKKAR u.a., Abendländische Akademie, Nürnberg 1963. Die thematisch eng zusammenhängenden Tagungen in Mainz und Eichstätt waren bereits vom konziliaren Prozeß inspiriert. Namhafte Teilnehmer waren evangelische und katholische Theologen, Philosophen, Historiker Sozialwissenschaftler und Politiker wie Joseph Lortz (Mainz), Raimondo Panikkar (Rom), Karl Rahner (Innsbruck), Georg Vicedom (Augustana-Hochschule Neuendettelsau), Wilhelm Stählin, Clemens Bauer, Arnold Bergstraesser (Freiburg), Arnold Gehlen (Speyer), Max Müller (München), Hans-Joachim von Rintelen (Mainz), Joachim von Merkatz, Richard Stücklen, Franz Herre, Nikolaus Monzel (München) sowie Heinrich von Brentano, Fraktionsvorsitzender der CDU/ CSU, der über die „Geschichtliche Verantwortung in der heutigen Welt" sprach (in: Das Europäische Erbe, S. 243 ff.). Im Oktober 1963 fand - nunmehr in den neuen Räumen der Pädagogischen Hochschule in Eichstätt - die letzte Jahrestagung der Abendländischen Akademie statt. Ihr Thema war: „Die Gesellschaft und ihr Recht“. Teilnehmer bzw. Referenten waren u.a. Joachim von Merkatz, Bundesverfassungsrichter Willi Geiger und der Soziologe Arnold Gehlen (Arbeitsbericht für 1963, in: Mitteilungsblatt der Abendländischen Akademie, Jg. 1 [1964], S. 3-5).

67 Bei Guido Müller/Vanessa Plichta, Zwischen Rhein und Donau (wie Anm. 5), S. 45 f. heißt es: „Ein Grund für die zunehmende Randständigkeit des abendländischen Denkens in der Bundesrepublik war sicherlich, dass die ,Abendländer', nachdem sie in den späten vierziger Jahren auch linkskatholische Überzeugungen vertreten hatten, mit Beginn der fünfziger Jahre zunehmend in rechtskonservative Kreise gerieten und in Opposition gegen das poli- 
der allerdings ebenso wenig die verschiedenen politisch-ideologischen und theologisch-konfessionellen Facetten ausleuchtet, die innerhalb der Eichstätter Akademietagungen erkennbar wurden. Der Eindruck der Homogenität von „Abendländischer Aktion“ und „Akademie“ wird ungebührlich verstärkt. So bemerkt Schildt - durchaus zutreffend -, dass „der gemeinsame Bezug auf das ,Abendland““ die Konfessionen nicht zuletzt auch in ihrem „Kampf gegen den vor allem als gottlos charakterisierten ,Bolschewismus “" zusammengeführt habe, doch scheint sein Zusatz, dass diese Art von Ökumene ,allerdings unter katholischer Suprematie" gestanden habe, fragwürdig. ${ }^{68}$ Offen bleibt nämlich, ob die katholische Suprematie quantitativ (z.B. Überzahl der Katholiken bei den Mitgliedern der Akademieorgane, den Referenten und den Teilnehmern der Akademietagungen) oder qualitativ (Protestanten folgen den Katholiken auch politiktheoretisch, theologisch-naturrechtlich o.ä.) zu verstehen ist. Zumindest letzteres ist zu bestreiten, da die Protestanten sich schwerlich unter die Führung des kirchlich-hierarchischen Lehrgebäudes, gar unter die Enzykliken der Päpste, gebeugt haben würden und vielmehr ihren eigenen, etwa in der Barmer Erklärung (Hans Asmussen) formulierten Zugang zum Staat im christlichen Abendland haben.

So nähren - trotz differenzierter Analysen in Einzelaspekten - Schildt und Müller/Plichta fälschlicher Weise den Eindruck einer fast nahtlosen Übereinstimmung von Abendländischer Aktion und Akademie. Auf die Ergebnisse von Helga Grebing und Martin Greiffenhagen, die in beträchtlichem Maße

tisch-gesellschaftliche System der Bundesrepublik traten." Welche rechtskonservativen Kreise die „Abendländer“ von ihren linkskatholischen Positionen (wie sie ähnlich in der Zeitschrift der Walberberger Dominikaner „Die Neue Ordnung “ und in den Sozialausschüssen der CDU vertreten wurden) weg ins traditionalistische Fahrwasser gezogen haben sollen, wird nicht gesagt. Offenbar vermögen sich die Autoren das - tatsächliche oder vermeintliche - Spannungsfeld zwischen sozialreformerischen Vorstellungen des „Neuen Abendlands“ und des „Abendländische Manifests" von Gerhard Kroll einerseits und die traditionalistisch-ständestaatlichen Vorstellungen andererseits nicht zu erklären.

68 Axel SCHILDT (wie Anm. 15), S. 197; eine gewisse Problematik des Protestantismus nach 1945 hinsichtlich anthropologischer und allgemein-sittlicher Begründungen und Rechtfertigung von demokratischem Staat, Verfassung, Grundrechten, christlichen Parteien u.ä. wird man nicht übersehen können (vgl. Hans-Gerd FISCHER, Evangelische Kirche und Demokratie nach 1945. Ein Beitrag zum Problem der politischen Theologie, Lübeck 1970) - ein Manko, das zu einer gewissen programmatischen Vorreiterrolle der Katholiken in der Union der frühen Jahre geführt hat, ohne dass allerdings die Protestanten den katholisch-naturrechtlichen Positionen gefolgt wären, wie sie vor allem im Kreis um das „Neue Abendland“ vertreten wurden. (Hermann Ehlers. Ausgewählte Reden, Aufsätze und Briefe 1950-1954, hg. von Karl Dietrich ERDMANN, Boppard 1991, S. 327, bemerkt, dass ,allgemein“ und auch im „besonderen Falle auf evangelischer Seite“ der katholische Naturrechtsbegriff „nicht übernommen werden“ kann. Den Katholiken empfiehlt er eine „sparsamere Verwendung“ des Naturrechts, den Evangelischen ,eine klarere Aussage über das Naturrecht"; vgl. auch Hans ASMUSSEN, Die evangelischen Kirchen nach der Wahl, in: NA 8 (1953), S. 723 f., ferner oben Anmerkung 12 und 13) 
die historische und ideengeschichtliche Forschung beeinflusst haben, wird nicht eingegangen. Immerhin hatte Helga Grebing ihre Behauptung einer beachtlichen Nähe von Abendländischer Aktion und Abendländischer Akademie durch ein theoretisches Konzept abgestützt: So verbindet die Autorin u.a. die Restaurationstheoretiker, wie sie die Abendländische Aktion und ihr Manifest kennzeichnen (Gerhard Kroll, Emil Franzel, Paul Wenger u.a.), mit der katholischen Staats- und Soziallehre, als deren Vertreter Theologen und Sozialethiker wie Gustav Gundlach, Johannes Messner, Jakob Hommes u.a. angeführt werden. Diese theoretisch-ideengeschichtliche Differenzierung ist so voraussetzungsvoll wie folgenreich. Grebing bemerkt, dass es hinsichtlich der Bemühungen um Wiederherstellung eines ,,christlichen Staates“ (im Sinne etwa Gerhard Krolls und der katholischen Staats- und Soziallehre ${ }^{69}$ einen grundlegenden gemeinsamen Bezugspunkt gibt: die ontologisch-normative Ordnungsidee, wie sie im Naturrecht der katholischen Kirche entfaltet ist (exemplarisch in der Rede Gustav Gundlachs). ${ }^{70}$ In der Tat wird man diesen Befund nicht leugnen können. Allerdings schließt diese Feststellung stillschweigend eine weitere Behauptung ein: dass nämlich die ontologisch-normative Ordnungsidee in dieser oder ähnlicher Form für den gesamten Katholizismus und damit wohl auch für die Katholiken innerhalb der Unionsparteien Geltung beanspruchen könne. Indem Grebing auf diese Weise den thomistischvorneuzeitlichen Vorbehalt gegenüber der Demokratie heraushebt, ist ihre These geeignet, den gesamten Katholizismus einer prinzipiellen Abwehrhaltung bezüglich des demokratisch-rechtsstaatlichen Denkens zu bezichtigen. Eine solche These ist jedoch nicht haltbar; sie lässt sich nicht einmal für die einschlägigen Beiträge der Eichstätter Akademietagungen belegen. Das Staatsund Verfassungsverständnis von Kroll, Franzel und auch Gundlach lässt sich schwerlich auf einen Nenner bringen mit dem der Verfassungsrechtler Hans Dombois, Ulrich Scheuner oder Adolf Süsterhenn, ungeachtet der Tatsache, dass letzterer als Katholik durchaus auf das katholische Naturrecht rekurriert. ${ }^{71}$

Die katholische Staats- und Naturrechtslehre, die Helga Grebing nur in kirchenoffizieller und theologisch-akademischer Version analysiert hat, ist

69 Vgl. Helga Grebing (wie Anm. 10), S. 263 ff.

70 Vgl. Helga Grebing (wie Anm. 10), S. 283 ff.; auf diese These stützt Martin GreIFFENHAGEN (wie Anm. 11) seine Annahme, dass die Gruppe um das Neue Abendland repräsentativ für den westdeutschen Konservatismus und seine Naturrechtsideologie nach 1945 sei.

71 Vgl. Adolf Süsterhenns Beiträge im Parlamentarischen Rat, Stenographische Berichte über die Plenarsitzungen (6. Sitzung vom 20.10.1948), Bonn 1948/49, S. 71 ff., die ganz selbstverständlich das verfassungstheoretische Instrumentarium wie Grundrechte, Gewaltenteilung, Verfassungsgerichtsbarkeit, pluralistische Entscheidungsbildung u.ä. voraussetzen. Dem neuscholastisch-organologischen Denken, das nicht mit Thomismus identisch ist, fiel dieser $\mathrm{Zu}$ gang zum liberalen Staatsdenken schwer; vgl. Paul MiKAT, Grundelemente katholischer Staatsauffassung, in: Karl Forster (Hg.), Christentum und Liberalismus, München 1960, S. 85 ff., $100 \mathrm{f}$. 
eben nicht identisch mit der Staats-, Verfassungs- und Gesellschaftstheorie, wie sie sich bei christlich-demokratischen Verfassungstheoretikern findet, die sich - sofern sie Katholiken waren - doch nur sehr allgemein auf die katholische Naturrechtslehre berufen haben und dies mühelos mit Demokratie verbinden konnten. ${ }^{72}$ Mögen sich bei den Akademietagungen in Eichstätt durchaus noch in nennenswertem Maße Reminiszenzen an die überkommenen Vorstellungen des integralistisch-konservativen Katholizismus des 19. und des frühen 20. Jahrhunderts gezeigt haben, so heißt dies weder, dass es in diesem Kreise nicht durchaus entschiedene Gegenstimmen gegeben hat, noch bedeutet dies, dass die traditionalistisch bis revisionistisch eingestellten Teilnehmer der Akademietagungen repräsentativ für den deutschen (politischen) Katholizismus oder Konservatismus im Umfeld der Unionsparteien gewesen sind. ${ }^{73}$ Bonn war nicht Eichstätt.

72 Vgl. Hans-Peter SchwarZ, Adenauer. Der Aufstieg 1876-1952, Stuttgart 1986, S. 495 ff., der - auf Adenauer und die frühe CDU-Programmatik bezogen - bemerkt, dass ,,auch nach 1945 “ nicht von einer einheitlichen katholischen Soziallehre ausgegangen werden kann, sondern vielmehr zwischen dem ganzheitlichen Ansatz der Dominikaner und der personal-individualistischen Staats- und Gesellschaftstheorie der Jesuiten unterschieden werden müsse. Dies ist zutreffend, doch ist die personalistisch-individualistische Position der Jesuiten als schultheologische Richtung neuscholastischer Prägung in den ersten beiden Nachkriegsjahrzehnten abzuheben von einem „christlichen Personalismus“ (Verantwortungsethik), wie er etwa die CDU-Programmatik seit dem Neheim-Hüstener Programm von 1946 kennzeichnet und schon geraume Zeit vor dem II. Vatikanischen Konzil (1962-1965) von Christen in Politik, Gesellschaft, Wissenschaft und Kultur vertreten wird (vgl. hierzu Rudolf UERTZ, Die Legitimität politischer Herrschaft. Das katholische Staatsdenken in Deutschland zwischen Naturrecht und politischer Theologie [1789-1965], Eichstätter Habilitationsschrift, Paderborn 2002).

73 Die Tagungen bieten u.a. auch Anschauungsmaterial zu den theoretischen Positionen von Vertretern der konservativen Deutschen Partei (u.a. Joachim von Merkatz; seit 1960 CDU; vgl. DERS, Aufgaben und Möglichkeiten einer konservativen Politik, in: Konservative Haltung in der politischen Existenz). Traditionalistisch-ständische und monarchistische Positionen fanden in den 50er Jahren Widerhall vor allem in den Gebieten Altbayerns im Umfeld der Bayernpartei und des Hundhammer-Flügels der CSU. 


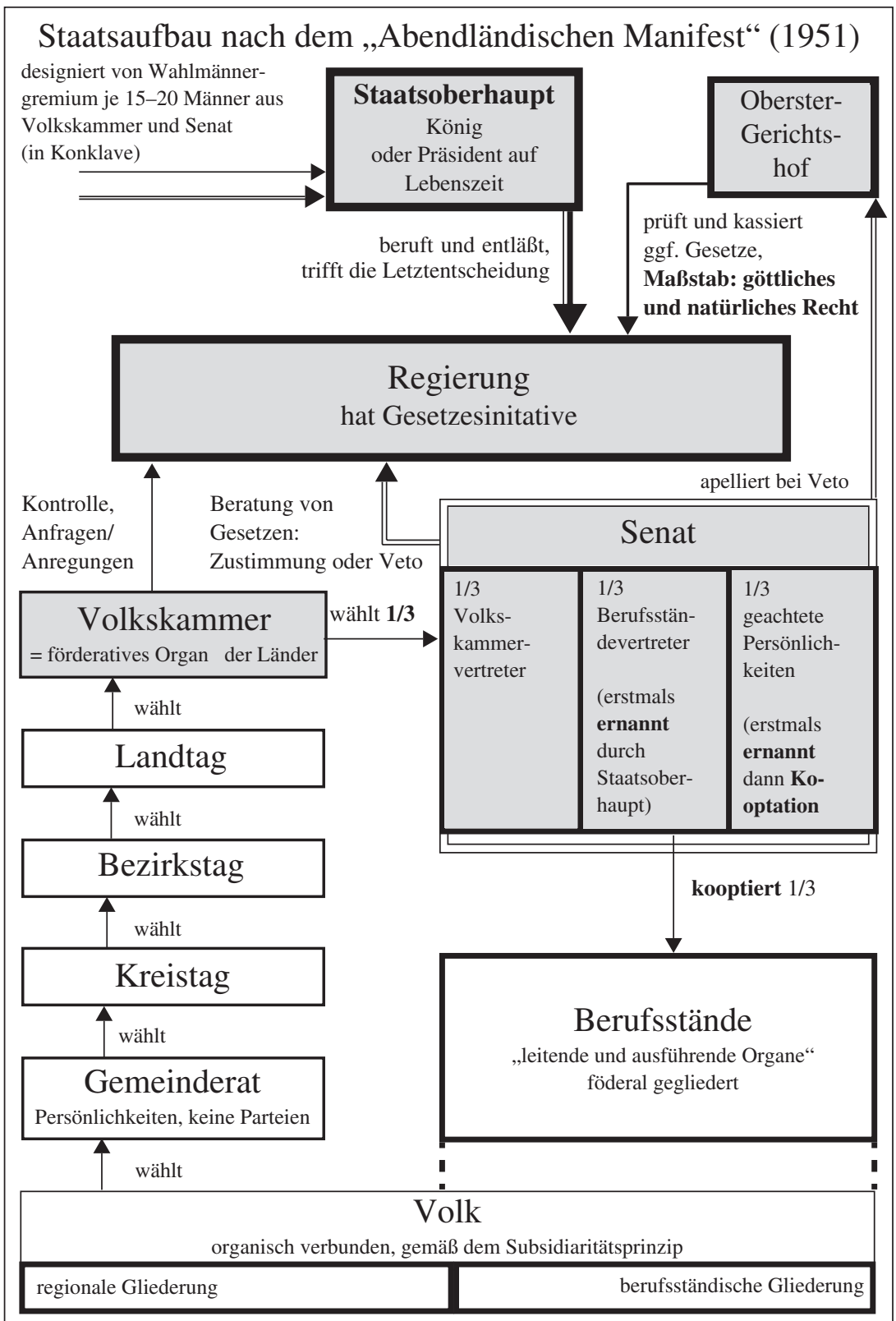

Das Organogramm bildet die verfassungstheoretischen Ausführungen Gerhard Krolls ab. 